\title{
State humility: Measurement, conceptual validation, and intrapersonal processes
}

\author{
Elliott Kruse ${ }^{\S}$, Joseph Chancellor and Sonja Lyubomirsky \\ University of California, Riverside, CA, USA
}

\begin{abstract}
Humility is a core psychological process theoretically marked by low self-focus, secure identity, and balanced awareness of strengths and weaknesses. We began with a consensual definition of humility before theoretically unpacking it. First, using 25 samples and 2622 adults, we developed the Brief State Humility Scale, which demonstrates strong construct validity and good reliability, is sensitive to experimental manipulation, and is uncorrelated with social desirability. Second, using this measure, we replicated previously reported relationships involving interpersonal processes; revealed links between state humility and intrapersonal processes (e.g. affect, creativity, and personality); and demonstrated key theoretical differences between state humility and modesty. This framework highlights new avenues for humility research and suggests how humility plays a critical role in emotional experience.
\end{abstract}

\section{ARTICLE HISTORY}

Received 24 February 2016 Accepted 18 November 2016 Published online 30 January 2017

\section{KEYWORDS}

Humility; emotions; personality; measure validation

\section{Introduction}

It is a truth universally acknowledged that claims of humility should not be trusted. Theoretically, humility is indicated by a balanced, secure, and non-distorted sense of one's strengths and limitations, as well as a lack of self-superiority and entitlement (Chancellor \& Lyubomirsky, 2013; Tangney, 2000). Assertions of humility are difficult to interpret because those who identify as humble may actually have an inflated sense of their strengths, and those who are humble may not even be aware of it (Davis, Worthington, \& Hook, 2010). Furthermore, as humility is viewed as socially desirable (Exline \& Geyer, 2004) and even virtuous (Dahlsgaard, Peterson, \& Seligman, 2005), awareness of one's humble feelings may lead to moral pride (Tangney, Stuewig, \& Mashek, 2007) and, ironically, a diminution of humility. Consequently, if people do not always accurately report their levels of humility, then measuring it promises to be challenging. Not surprisingly, measurement has remained a persistent hurdle (Chancellor \& Lyubomirsky, 2013; Davis et al., 2010).

\section{Potential contributions of research on humility}

The measurement obstacle is worth surmounting, however, because research on humility may contribute to core theoretical questions about the self, emotion, and motivation, as 
well as to the development of practical interventions that may improve social and individual well-being. Addressing theory, we propose, first, that research on humility can illuminate the workings of central, self-oriented processes, such as self-esteem and self-focus. The importance of the self in psychological theory cannot be overstated; however, discussions about self-oriented processes typically focus on their effects, both adaptive (e.g. Judge, Erez, \& Bono, 1998) and maladaptive (e.g. Baumeister, Smart, \& Boden, 1996). The centrality of the self is itself rarely questioned (Leary \& Guadagno, 2011; Tangney, 2000). Research on humility, which is showing that humble people lack self-focus (e.g. Kruse, Chancellor, Ruberton, \& Lyubomirsky, 2014; Ruberton, Kruse, \& Lyubomirsky, 2016), presents a novel opportunity to critically analyze self-oriented processes and their centrality. In normal psychological functioning, a focus on the self may prove to be common, but not essential.

Second, humble feelings are likely to play a role in emotion processes - for example, as causes, consequences, or mediators of emotions such as awe (Chancellor, Cornick, Nelson, Blascovich, \& Lyubomirsky, 2016) and gratitude (Layous, Nelson, Kurtz, \& Lyubomirsky, 2016). The ability to capture moment-to-moment or day-to-day experiences of humility may help researchers build theories of emotion and discover previously undetected pathways between emotion, motivation, and their antecedents and outcomes. Humble feelings appear to mediate the relationship between gratitude and motivation to become a better person, by stimulating people to prove themselves worthy of a benefactor's help (Layous et al., 2016).

In addition to this potential theoretical importance, research on humility also holds promise for practical application. First, developing humility interventions may serve as a critical antidote to toxic self-focused qualities, such as narcissism and entitlement (Paulhus \& Williams, 2002; Raskin \& Hall, 1979). Recent research suggests that the prevalence of narcissism has increased in recent generations (Twenge, Konrath, Foster, Campbell, \& Bushman, 2008) and increasing the frequency of humble experiences in the population may help stem this tide. Second, research on humility contributes to a developing literature on "self-less" paths to well-being (Exline, 2008; Leary \& Guadagno, 2011). Excessive self-focus may lead to an easily threatened ego (Baumeister et al., 1996), which may, in turn, relate to feelings of anxiety (e.g. Rhodewalt \& Morf, 1998), depression (e.g. Pyszczynski \& Greenberg, 1987), and aggression (e.g. Stucke \& Sporer, 2002), whereas manipulations of generosity and gratitude boost well-being by reducing focus on the self (Chancellor, Bao, \& Lyubomirsky, 2014; Kruse et al., 2014). In short, humility may serve as a tonic for traditional sources of negative affect and open new paths to happiness and satisfaction (Chancellor \& Lyubomirsky, 2013).

Lastly, humility is related to a wide range of socially desirable, prosocial outcomes (Ashton \& Lee, 2008; Exline \& Hill, 2012; Hilbig \& Zettler, 2009) and may serve as a core moderator in many interpersonal behaviors (Chancellor \& Lyubomirsky, 2013). For example, humble doctors are more likely to have healthy patients (Ruberton, Huynh et al., 2016). In particular, humility may have broad benefits in organizational settings (Owens, Rowatt, \&Wilkins, 2011) and may be a key facet of strong leadership (Morris, Brotheridge, \& Urbanski, 2005; Owens \& Hekman, 2012).

\section{Opportunities in contemporary research on humility}

Despite this nascent promise and burgeoning research, the humility literature has neglected three lines of inquiry. First, humility has been measured almost exclusively as a trait. Although traits play a critical role in psychological theory, they are by definition more stable than states 
and therefore may be relatively less responsive to experimental manipulation. To be sure, traits play an important role in experimental work, but they may be comparatively less useful than states as experimentally manipulated variables themselves. As such, the direction of the correlations between trait humility and its nomological network has not yet been clearly tested.

Second, humility has been assessed primarily using other-reports. (A notable exception involves self-report measures used to assess relatively more broad traits [e.g. HEXACO "Honesty-Humility," which by its title encompasses more than merely humility] and closely related but separable traits [e.g. NEO "Modesty"]. Both Honesty-Humility and Modesty are discussed in depth in Study 2b). Although the other-report approach is useful because it can avoid the social desirability biases discussed above, it is contingent on peoples' abilities to judge humility accurately. As such, using other-reports may unnecessarily conflate humility with related constructs that are more conspicuous, such as modesty (e.g. Cialdini, Wosinska, Dabul, Whetstone-Dion, \& Heszen, 1998) and agreeableness (e.g. Graziano, JensenCampbell, \& Hair, 1996).

Third, researchers have primarily explored humility's relationships with interpersonal constructs, such as generosity (Exline \& Hill, 2012) and cooperativeness (Hilbig \& Zettler, 2009), and have not yet focused on intrapersonal ones, such as well-being and cognition. Although humility is commonly viewed as a characteristic that is related to strong social relationships (Davis et al., 2011), it is likely to have distinct benefits for the self as well. Although seemingly unrelated, these three limitations are actually connected, as self-report may prove the best way to measure intrapersonal responses to experimental manipulations and transient life events. Addressing these issues opens novel research questions about the theoretical contours of humility.

\section{The present approach}

In this project, we aim to explore state humility's network of theoretically-derived relationships and, to this end, to develop and validate a measure of state humility. To establish validity, we employ two principal empirical strategies - exploring the measure's nomological network (Cronbach \& Meehl, 1955) and demonstrating that changes in underlying humility cause changes in the humility measure (Borsboom, Mellenbergh, \& van Heerden, 2004).

Our approach is to begin with a consensual definition of humility. Research on humility is still new, and we do not want a priori theoretical assumptions to be embedded in the measure and influence later research. For example, if humility is conflated with closely related constructs (such as modesty), then a measure built on that conflation will yield erroneous relationships. Across the present studies, we seek first to measure the construct as it is found in the world (i.e. the quality that other people would recognize as humility), then to examine its relationship with a broad range of relevant constructs, and, lastly, to integrate these results to unpack the consensual definition into a new theoretical definition.

With respect to methodological concerns, our research seeks to show that, despite investigators' prior concerns, a self-report measure of humility can be valid and convergent with other-reports. Additionally, our studies aim to provide evidence that humility can be statelike and that our self-report measure is sensitive to manipulation. Lastly, we seek to demonstrate the breadth of humility's relationships by expanding its network of correlates. In particular, we aim to extend prior research by testing whether humility is solely interpersonal 
and prosocial or whether it can have intrapersonal benefits in disparate areas such as affect and creativity. Through these contributions, we seek to develop a new framework of the core aspects of humility.

\section{Humility as a state}

Humility has been traditionally conceptualized and measured as a trait (Chancellor \& Lyubomirsky, 2013; for an exception, see Tangney, 2000). This approach is useful for many research questions, such as whether dispositional factors predict prosocial behaviors (e.g. Exline \& Hill, 2012). However, viewing humility exclusively as a trait suggests that experimenters may only be capable of manipulating external, situational factors, but not the "trait" humility itself. Furthermore, to our knowledge, no evidence exists to support the assumption that it is solely a trait. We propose that complementing trait-based research with a state approach to humility can address important theoretical and methodological questions. We do not believe that any singular approach is sufficient on its own and both state and trait perspectives of humility are needed.

From a theoretical perspective, by allowing that humility may fluctuate day to day, hour to hour, and even minute to minute, several new research questions become available. If humility can rise and wane over short periods of time, it can be experimentally boosted and lowered. As such, the state approach opens questions about what precedes, causes, and results from shifts in humility. Additionally, the state approach makes possible the study of how trait humility develops - for example, whether people acquire humility (or lose it) in response to humbling (or ego-inflating) life events (e.g. birth of a child, unexpected success), through slow growth over time due to small daily events (e.g. loving one's spouse, expressing gratitude to co-workers), or a combination of these and other factors (e.g. genetics, values). Lastly, the state approach has implications beyond humility itself to questions about the dynamic nature of self and self-focus (Exline, 2008; Leary, Adams, \& Tate, 2006), as well as about what thoughts, emotions, and behaviors precede, follow, or co-occur with humble feelings, as they arise in real time.

Methodologically, the state approach facilitates at least two kinds of research designs. First, it lends itself to building a state measure of humility that may be used as a manipulation check. Presently, the lack of such a measure impedes experimentation. Second, state humility can be explored in non-experimental prospective investigations, as well as daily diary and experience sampling studies. Unlike trait-based studies, in which temporal variability is often interpreted as error, a state approach assumes that change across time may be substantively meaningful and correlated with other psychological factors.

\section{Self-report measure of humility}

Humility notoriously does not lend itself well to measurement (Davis et al., 2010). As discussed above, by definition, the construct of humility resists direct report: Those who call themselves humble may be self-aggrandizing and those who truly are may not be aware of it or reluctant to report it (Davis et al., 2010, 2011). Given this paradox, most previous researchers have regarded self-report measures of humility to be unfeasible or deceptive and have preferred to use indirect measures instead (e.g. Rowatt et al., 2006). One of the most common approaches is other-report, in which known acquaintances rate a target on 
humility, and these ratings are correlated with theoretically relevant outcomes. Accordingly, several other-report measures have been developed (Davis et al., 2011; Owens, 2009). An alternative indirect methodology involves using implicit association tests (IATs) of humility that draw on subtle associations between the self and humility concepts (Rowatt et al., 2006).

Although current approaches to the measurement of humility resolve several problems, they are not sufficient for addressing all theoretical and methodological concerns. First, other-reports of humility are theoretically problematic because humility is an internal quality, whereas related constructs like modesty and agreeableness are external (Graziano et al., 1996; Sedikides, Gregg, \& Hart, 2008) and higher in judgeability (Funder, 1995). Other-ratings can only gauge humility insofar as humility is expressed by the target and perceived by the rater; to the degree to which these processes fail to occur, the validity of the rating is weakened. Furthermore, situations vary in how relevant humility is and thus how detectible it is (Chancellor \& Lyubomirsky, 2013; see also Funder, 1995). Given these issues, other-ratings of humility may overestimate the relationship between humility and modesty and systematically skew the network of observed relationships between humility and its correlates.

Second, other-reports typically tap raters' knowledge of the target's stable characteristics; in other words, they are really trait measures. As a result, most other-reports are of limited use for experimental designs or diary studies. Even if raters are asked to judge an individual's humility at a specific moment (i.e. his or her state humility), they may still be influenced by their preconceptions of that individual's trait humility, thus inaccurately inflating state humility's stability.

Third, other-reports - if they come from acquaintances, friends, or family - may be plagued by social desirability concerns, as judges strive to present the target in a positive light (Klar \& Giladi, 1997). Although frequently theorized, current research has yet to establish that other-reports of humility truly are free from social desirability bias. Furthermore, knowledge of other positive qualities of the target may bias ratings of the target's humility via a halo effect (Nisbett \& Wilson, 1977).

Alternative approaches, such as IATs, solve several of these problems, but present other challenges. Unlike other-reports, the IAT does not correlate with social desirability (Rowatt et al., 2006) and, because it is completed by the participant herself, may offer greater access to the intrapersonal aspects of humility. However, it has not yet been shown to correlate strongly with theoretically related constructs (Rowatt et al., 2006; cf. LaBouff, Rowatt, Johnson, Tsang, \& McCullough Willerton, 2012). Furthermore, administration of the IAT requires specialized software and therefore is difficult to implement in non-laboratory studies and unsuitable for tapping real-time fluctuations in state humility. To be clear, other-reports and IATs can be effective and valuable tools for measuring humility. However, they do not solve all methodological problems and must be used in concert with other approaches to maximize theoretical validity.

To complement these approaches, we suggest that a self-report approach is both possible and necessary. We propose that the paradox of reporting - those who claim to experience it likely don't (Davis et al., 2011) - is only an issue with transparent self-ratings of humility. In a self-rating, respondents are asked to describe their humility explicitly - for example, to rate their agreement with an item like, "I am a humble person," or to rate themselves on a scale from "arrogant" to "humble" (e.g. Rowatt et al., 2006). Self-ratings render the meaning of the scale obvious and allow participants to present themselves in a positive light. 
However, not all self-reports need be so explicit. We propose two strategies to address concerns with such self-ratings. First, a self-report measure of humility should not inquire about humility directly - indeed, the optimal prompt should not use the term "humility" at all. Rather, an indirect self-report approach asks about the views, attitudes, or feelings that a humble person possesses. Second, indirect prompts should include the construct's negative aspects in addition to its positive aspects (e.g. focusing on the costs or sacrifices associated with the desirable trait) to minimize their social desirability. For example, although many people may wish to describe themselves as "humble," relatively few may want to identify themselves as "no better or worse than the average person."

We submit that indirect self-report measures of humility are essential because they allow for more direct access to the construct and thus may be more theoretically valid relative to other measures. As discussed above, other-reports may bias ratings of humility toward more conspicuous constructs, such as modesty or agreeableness, and this bias may prove critical when humility and these constructs diverge theoretically in their relationships with outcomes. For example, if humility is related to a secure sense of self and a willingness to express oneself authentically (Chancellor \& Lyubomirsky, 2013; Tangney, 2000), then those in a humble state may be likely to engage in positive deviance and defy groups norms when they feel it is ethically necessary (Spreitzer \& Sonenshein, 2004). By contrast, a modest individual may be unlikely to disrupt group norms (Sedikides et al., 2008). Self-report measures may be used in these cases to disentangle two theoretically close constructs, whereas otherreports, especially those obtained from other group members, may confound measurement.

Relatedly, self-report measures provide unique information that other-report cannot and may be better suited to some research questions. For example, self-report can tap humility-relevant beliefs and emotions, which are not immediately accessible to others. Whereas the first point concerns humility as a predictor, this second consideration concerns humility as an outcome. Humility may fluctuate in response to stimuli or across time frames in ways that are not always observable to others. For example, an individual experiencing a humbled state due to a moment of gratitude or awe may not convey or communicate this momentary shift. Important events, or even laboratory manipulations, may elicit humility-relevant changes that are invisible to others but salient to the individual; self-report is the only way to measure such changes.

\section{Overview of studies}

In Study 1, we present the development of the Brief State Humility Scale (BSHS) including analysis of its factor structure and temporal variability. Studies $2 \mathrm{a}$ and $2 \mathrm{~b}$ examine the convergence of self-reported state humility in predicting positively-related constructs such as trait humility, and negatively-related constructs, such as narcissism, entitlement, and pride. We also show discriminant validity with self-esteem and social desirability. In Study 3, we expand our investigation of the BSHS to other intrapersonal (e.g. affect, personality, creativity) and interpersonal (e.g. forgiveness, empathy, social dominance) constructs. Finally, in Study 4 , to validate our conceptualization of humility as a mutable state, we show that state humility is sensitive to experimental manipulation - namely, that levels of state humility can be boosted via self-affirmation and gratitude inductions and reduced via hubristic pride inductions. 


\section{Online samples}

Across all our online subsamples, we recruited a total of 2622 adult participants ${ }^{1}$ (female $=1272 ; 48.51 \% ; 3$ did not report gender) from Amazon's Mechanical Turk (Buhrmester, Kwang, \& Gosling, 2011). The mean age was 33.35 (SD = 11.82).

\section{Subsampling strategy}

Because we are validating a state measure, we employed multiple subsamples, rather than a single, comprehensive battery of measures as is standard in trait validation studies. A subsample that closely pairs state humility in time with another measure clarifies their true relationship and minimizes extraneous "noise" that might arise from contamination, boredom, or time. For example, a measure in a battery of surveys could inadvertently influence the state construct of interest (e.g. completing a depression scale might elicit depression; e.g. Larsen \& Sinnett, 1991; Velten, 1968). Thus, restricting each subsample to complete a pair of measures limits carry-over effects. Likewise, a barrage of surveys may elicit feelings of boredom, frustration, or even interest, and these may have substantive effects on our state variable (e.g. confusion may be ego-threatening, which may reduce humility; Exline, 2008). Lastly, time itself may have effects on the variable of interest, as the state fluctuates naturally. Thus, to address these possible confounds, we employed a targeted subsampling approach.

This sampling strategy resulted in 342 participants ( $13.8 \%$ of the total sample) completing two or more batteries. Of these, 241 (9.7\%) participated in no more than two samples, 67 $(2.7 \%)$ in three samples, and $34(1.4 \%)$ in four or more samples. The overlap in participants was not problematic (and was even advantageous) ${ }^{2}$ because their proportion was relatively small, each pair of measures in the subsample was self-contained, and none of our studies employed deception or required secrecy. Thus, we felt that carry-over effects between subsamples were unlikely to strongly bias the entire subsample. Furthermore, excluding these participants from our analyses did not substantially change the results.

\section{Demographics}

With respect to ethnicity, 15 (1.0\%) identified as American Indian or Native Alaskan, 174 (7.0\%) as Asian/Asian-American, 202 (8.1\%) as Black/African-American, 16 (0.6\%) as Hawaiian/ Pacific-Islander, 120 (4.8\%) as Hispanic/Latino, 1884 (75.8\%) as White, 75 (3.0\%) as other or more than one ethnic identity, and one did not report ethnicity $(0.1 \%)$.

With respect to highest level of education attained, 41 (1.6\%) reported completing some high school, 317 (12.7\%) high school or equivalent, $1040(41.8 \%)$ some college (including community college), 732 (29.4\%) bachelor's degree, 178 (7.2\%) some graduate education, 116 (4.7\%) professional degree (e.g. law, medicine), 19 (0.8\%) Ph.D., and 5 (0.2\%) did not report education.

\section{Screening}

In samples with longer measures (e.g. the HEXACO personality measure; Lee \& Ashton, 2004), we included distraction probes (e.g. "If you read this, please mark'agree'"') to ascertain participants' attentiveness during the study. Of the 1372 participants who completed batteries with distraction probes, 90 (6.56\%) participants failed the probe. We report the failure rates in each sample with the results. All analyses on samples with distraction probes did not include the participants who failed the probe. 


\section{Study 1}

Study 1 included the initial development of the BSHS, exploration of its factor structure, and documentation of its stability across time. We did not first adopt a definition of humility and conform our items to it. Rather, at this stage of research, we felt the most useful definition was, "What other people perceive as humility." As such, we employed a bottom-up approach in which humility-relevant items were collected from participants, coded, and used to generate the scale items.

Taking this approach, we expected our scale to demonstrate a single factor structure. Although humility has been defined at times as having multiple aspects (e.g. Tangney, 2000), we did not adopt a multidimensional (or multiple scale) approach. We did this for several reasons. First, although humility may have multiple facets, they do not necessarily need to be measured independently at all times (e.g. extraversion is a theoretically useful construct, independent of its components). Second, given that little empirical work has yet clarified the definition of humility, we did not know what targeted approaches would be most appropriate. In other words, we needed first to measure humility before we could unpack it. Lastly, practically, we wanted an instrument that would facilitate experimentation (e.g. for a brief measure after a manipulation), and so opted for a short measure. The brevity impedes many multi-scale approaches.

\section{Method}

\section{Samples}

We employed samples of both online participants (Samples 1a, 1b, and 1d), as well as an undergraduate sample (Sample 1c).

Sample 1a. We recruited a sample of participants $(N=24)$ to answer open-ended questions about humility for item generation.

Sample 1b. To investigate the factor structure of the final six items, we recruited a sample of online participants $(N=202)$ to complete these items. Of these, 10 either perseverated (marked the same number for five or more of the questions) or reported being distracted; they were not included in analysis (final $n=192$ ).

Sample 1c. To examine test-retest reliability over time, we recruited undergraduates $(N=48)$ in exchange for course credit from an ethnically diverse U.S. university. Participants completed all six items every day for 2 weeks as part of a larger daily diary study on gratitude (see Study 3; Kruse et al., 2014). The average completion rate was $72.7 \%$ and participants submitted a total of 714 daily surveys.

Sample 1d. Finally, as further validation of test-retest reliability, we examined the entire sample of online participants to identify those who had participated in more than one subsample and had thus taken the BSHS at least twice $(N=342)$.

\section{Scale development}

Participants (Sample 1a) were asked to list five statements that they thought a humble person would "say or agree with." The participants were instructed that the statements could also be beliefs, views, or anything that a humble person might "endorse about themselves, others, or the world." The resulting 124 items were coded for common themes. 
Twelve themes emerged: environment appreciation ("The earth is an amazing place"), egalitarianism ("No one is better or worse than anyone else"), gratitude ("I couldn't have done it without you"), other-appreciation ("I respect all people and their traditions"), limitations ("I'm not really good at that"), others-better ("You play the flute so much better than I do"), averageness ("I'm no better than the next guy"), pride avoidance ("Don't brag about your accomplishments"), prosociality ("I am happy to help"), ignorance ("I'm sure you know more about it than I do"), nonmaterialism ("Collecting worldly possessions is not important"), and apologies ("Please forgive me for causing so much trouble. It won't happen again.").

Some of the statements were coded as having more than one theme. The themes were then tallied. Admission of averageness and of limitations were two of the most common themes, along with recognition of the relative strengths of others ("others-better") and egalitarianism. These themes echoed similar conceptions in theory on humility (e.g. Chancellor \& Lyubomirsky, 2013; Tangney, 2000). As the measure was intended to be brief, we could not include all 12 themes. Thus, we focused the item creation on the dominant four themes.

We interpreted some of the themes (e.g. gratitude, apologies) as being part of the theoretical network of humility but not the construct itself (Chancellor \& Lyubomirsky, 2013). For example, a humble individual may apologize more than others, but people may also apologize for reasons unrelated to humility, and a humble person may at times choose not to apologize. Although related, humility and apologizing are different, and so we did not include apology items in the measure. Some of these other themes have been found to be independent constructs and antecedents of humility (e.g. gratitude, Kruse et al., 2014; environment appreciation, Chancellor et al., 2016). Others we explore later in this paper as correlates (i.e. prosociality, pride avoidance).

Using these themes as guides, six items were generated that represented the breadth of responses given (see Appendix 1). We did not directly adopt the statements provided because many referred to specific contexts or situations (e.g. "Anyone could have done it," or "I did my part, nothing more"). To generate the items, we constructed first-person descriptions of the self to reflect the respondents' momentary self-concept. To distinguish from modesty, we focused on how respondents perceive themselves and not how others perceive them.

To create reverse-coded items, three of the items were phrased as opposites of the given statements. As discussed previously, to mitigate social desirability, none of the items included "humility," "humble," or similar terms, and the positively-coded items were designed to include socially undesirable aspects, such as admission of weakness. The phrase "I feel" was appended to all items and the instructions were written to emphasize the transitory nature of the humble perspective (i.e. "Please answer these questions based on how you feel right this moment"). Although we theorize that state humility is a cognitive state, we used the words "I feel" rather than "I think," because "I think" can connote one's relatively fixed perspective or opinion (e.g. "I think coffee is better than tea"), whereas "I feel" better communicates that what follows is a type of transitory and subjective experience (e.g. "Right now, I feel I like coffee better than tea").

\section{Results and discussion}

\section{Single factor structure}

Because we had an a priori hypothesis about structure, we did not conduct an exploratory factor analysis to select the best items. We conducted a confirmatory factor analysis to test whether a single-factor solution fit the data well, which it did: $\mathrm{CFI}=.95, \mathrm{RMSEA}=.08, \mathrm{SRMR}=.05$. 
Test-retest reliability

To assess the temporal variation of the measure, we examined only participants' first and last scores over 14 days (Sample 1c), which were highly correlated, $r(29)=.688, p<.001$. The correlations between the first measurement occasion and any other measurement occasion were similar, $M_{\mathrm{r}}=.621, \mathrm{SD}_{\mathrm{r}}=.061$. These results were part of a larger set of analyses on within-person change in state humility (Kruse et al., 2014). In this prior study, humility fluctuated naturally across 14 days; additionally, it predicted and was predicted by daily changes in people's levels of gratitude. These results provide evidence that humility fluctuates and that this fluctuation is substantively meaningful.

Finally, using results of online participants who completed multiple batteries (Sample $1 d$ ), we examined only the correlations between the first and second completions. The median number of days between measurement occasion was 14.46, and the two time points were positively correlated, $r(334)=.45, p<.001$.

To our knowledge, no normative criterion for test-retest reliability exists. For comparison, this correlation is similar to that of a measure of state affect $(r=.54$; Positive Affect/Negative Affect schedule; Watson, Clark, \& Tellegen, 1988) and lower than a short-form measure of Big Five personality traits ( $r=.80$; Gosling, Rentfrow, \& Swann, 2003).

\section{Study 2a: Construct validity}

In our second study, we sought to establish convergent validity by correlating humility with related constructs - a mix of states and traits - with expected positive and negative relationships, including trait humility, narcissism, entitlement, and hubristic pride. We also aimed to show that self-reported state humility converges with observer ratings of humility. Finally, we sought to demonstrate humility's discriminant validity from constructs such as self-esteem, authentic pride, and social desirability.

We expected trait humility to strongly correlate with our measure of state humility; people high in trait humility are likely to experience more frequent humble states than others. With regard to narcissism, psychologists disagree on the proper conceptualization of narcissism, and correlations between different measures can be low (Maxwell, Donnellan, Hopwood, \& Ackerman, 2011). Nonetheless, we expected state humility to generally correlate negatively with narcissism - and strongly so for maladaptive aspects of narcissism (e.g. exploitativeness, superiority, and entitlement). Along the same lines, we expected state humility to negatively correlate with hubristic pride, which is conceptualized as a negatively-valenced "self-conscious" emotion (Tracy \& Robins, 2007).

We also sought to establish discriminant validity from three theoretically distinct constructs: self-esteem, authentic pride, and social desirability. Theoretically, humility and self-esteem represent two separate factors. Humility involves low self-focus (Chancellor \& Lyubomirsky, 2013; Tangney, 2000), whereas self-esteem involves a high sense of self-worth (Rosenberg, 1965). As humility entails an awareness of both strengths and weaknesses, it should not relate strongly to self-esteem. However, as humility is related to a secure sense of self, the two constructs could relate positively. Given all these theoretical nuances, we expected a weak (albeit positive) correlation between self-esteem and state humility.

Although authentic pride is conceptualized as a positively-valenced "self-conscious" emotion (Tracy \& Robins, 2007), we had several reasons to expect that it would have only a weak relationship to state humility. First, we conceptualize high state humility as reflecting 
relatively low self-focus (Chancellor \& Lyubomirsky, 2013), in contrast with authentic pride's explicitly high self-focus. Authentic pride is also highly agentic and achievement focused (e.g. items include adjectives such as "accomplished,"'achieving," and "productive"), and positively correlates with extraversion, self-esteem, and narcissism (Tracy \& Robins, 2007).

Prior efforts to create and validate a self-report measure of humility have found that such a measure positively correlates with social desirability (e.g. Rowatt et al., 2006). This positive relationship suggests that respondents are distorting their answers by claiming humility which is generally seen as a positive trait (Exline \& Geyer, 2004) - and thus undermining the measure's validity. As mentioned previously, we took specific steps to avoid this possibility by not using the words "humility" or "humble" among our items and carefully balancing the items' apparent social desirability. Consequently, we expect our measure of state humility to differentiate itself from social desirability by having no relationship or a weak negative relationship.

\section{Method}

\section{Samples}

Continuing our subsampling approach, each construct measure was paired with the BSHS in a separate sample. We report the size of the subsample in the results for each measure.

\section{Measures}

HEXACO Honesty-Humility. The HEXACO personality inventory (Lee \& Ashton, 2004) consists of 100 self-descriptive statements (e.g. "I would be quite bored by a visit to an art gallery," and "When working, I often set ambitious goals for myself") rated on a scale of 1 (strongly disagree) to 5 (strongly agree). It has six major scales and one interstitial scale; we presently focus on Honesty-Humility, as it directly bears on the construct validity of the BSHS. The other scales of the HEXACO from this sample are examined in Study 3. The modesty subscale is examined in further detail in Study $2 b$.

Narcissistic Personality Inventory. The Narcissistic Personality Inventory (NPI; Raskin \& Hall, 1979) comprises 40 forced-choice items ( $\alpha=.90$; e.g. "I am a born leader" and "Leadership is a quality that takes a long time to develop") that comprise seven subscales (see Raskin \& Terry, 1988 for further detail on subscales).

Pathological Narcissism Inventory. The Pathological Narcissism Inventory (PNI; Pincus et al., 2009) consists of 52 items that, in turn, comprise two higher-order subscales and seven lower-order subscales ( $\alpha=.92$; see Wright, Lukowitsky, Pincus, \& Conroy, 2010 for more information about subscales). Example items include "I can make anyone believe anything I want them to," and "I get annoyed by people who are not interested in what I say or do."

Personal Entitlement Scale. The Personal Entitlement Scale (PES; Campbell, Bonacci, Shelton, Exline, \& Bushman, 2004) consists of nine items ( $\alpha=.87$; e.g. "I honestly feel I'm just more deserving than others" and "I demand the best because I'm worth it") rated on a scale of 1 (strongly disagree) to 7 (strongly disagree). 
State pride. The state Authentic/Hubristic pride scales (Tracy \& Robins, 2007) each consist of seven items (e.g. "accomplished," "smug"), rated on a scale of 1 (not at all) to 5 (extremely) for the extent that each is felt by the participant at that very moment. The authentic pride scale taps feelings of success and confidence $(\alpha=.92)$ and the hubristic pride scale taps feelings of superiority and haughtiness $(\alpha=.92)$.

Social desirability. The Balanced Inventory of Desirable Responding (BIDR; Paulhus, 1991) includes 40 self-referential statements $(\alpha=.86)$ that are rated on a scale of 1 (not true) to 5 (very true); items are re-coded such that only extreme agreement is scored and summed. The BIDR comprises two subscales - self-deceptive enhancement (e.g. "I never regret my decisions;" $\alpha=.81$ ) and impression management (e.g. "I never cover up my mistakes"; $\alpha=.74$ ).

Self-esteem. The Rosenberg Self-Esteem measure (RSE; Rosenberg, 1965) consists of 10 items (e.g. "I take a positive attitude toward myself"; $\alpha=.87$ ) scored on a scale of 1 (strongly disagree) to 4 (strongly agree).

Observer ratings. Participants completed an open-ended essay prompt in which they imagined that someone was angry with them. They were then asked to describe why this person was angry and what their response would be. The prompt was intended as a "stress test" of humility that makes participants' humility salient because it provides them an opportunity to acknowledge their capacity to transgress against others (Chancellor \& Lyubomirsky, 2013).

These essays were rated on two separate criteria. First, a group of five judges (one female, four male) recruited online (mTurk; mean age $=38.4, \mathrm{SD}=15.32$ ) rated participants' responses using their lay definition of humility. They assessed how humble and arrogant they felt the participant was (e.g. "This person is humble") on a scale of 1 (strongly disagree) to 5 (strongly agree). The arrogance ratings were reverse-coded to create a humility composite ( $\alpha=.84$; $I C C[2,1]=.35)$. Second, a different group of five judges, comprised of three females and two males, recruited online (mTurk; mean age $=30.8, S D=13.83$ ) rated the participants' essays, using the same response scale, on a theoretically-defined set of questions; specifically, they completed an other-directed form of the BSHS (e.g. "This person feels that, overall, they are no better or worse than the average person"; $\alpha=93 ; I C C[2,1]=.31$ ).

\section{Results}

Bivariate correlations are displayed on Table 1.

\section{HEXACO honesty-humility}

Two hundred and sixty-three participants completed the HEXACO and then the BSHS. Twenty-four (9.1\%) failed the distraction probe and were excluded, yielding a final sample size of 239. The Honesty-Humility scale ( $\alpha=84$ ) correlated positively with the BSHS $(\alpha=.85)$, $r(237)=.49, p<.001$ (see Table 2 for Honesty-Humility subscale correlations and alphas; the remainder of Table 2 will be relevant to Study 3 ).

\section{Observer ratings}

Sixty-five participants completed the open-ended prompts as a part of a larger program of experiments (Kruse et al., 2014). The self-report BSHS ( $\alpha=.83$ ) correlated well with both the 
Table 1. Correlations between Brief State Humility Scale and measures in Study 2a.

\begin{tabular}{lccc}
\hline & $\mathrm{df}$ & $r$ & $p$ \\
\hline $\begin{array}{l}\text { Observer-ratings } \\
\text { Lay ratings }\end{array}$ & 63 & & \\
$\quad$ Other-rated BSHS & & 0.48 & $>0.001$ \\
$\quad$ Entitlement & 99 & 0.64 & $>0.001$ \\
State pride & 185 & -0.55 & $>0.001$ \\
$\quad$ Hubristic pride & & -0.41 & $>0.001$ \\
$\quad$ Authentic pride & & -0.05 & 0.484 \\
Social desirability & 280 & -0.03 & 0.624 \\
$\quad$ Self-deceptive enhancement & & 0.06 & 0.334 \\
Impression management & & 0.03 & 0.787 \\
$\quad$ Self-esteem & 87 & & \\
\hline
\end{tabular}

Note: Blank spaces have an equal value to the cell above them.

judges' lay definition of humility, $r(63)=.41, p=.001$ and the other-report BSHS, $r(63)=.48$, $p>.000$. The lay definition of humility and the other-report BSHS also correlated strongly, $r(63)=.64, p>.001$.

\section{Narcissism and entitlement}

One hundred and two participants completed the NPI and then the BSHS ( $\alpha=.81)$. Three (2.9\%) participants failed the distraction probe and were not included ( $n=99)$. The NPI negatively correlated with state humility, $r(97)=-.64, p<.001$. Additionally, all of the NPI's individual subscales also correlated with state humility (see Table 3 for correlations and alphas).

Ninety-nine participants completed the PNI and then the BSHS $(\alpha=.76)$. Three participants failed the distraction probe and were not included $(n=96)$. The PNI negatively correlated with state humility, $r(96)=-.20, p=.047$. Unlike the NPI, only two of the PNI subscales (Exploitativeness and Entitlement-Rage) correlated significantly with state humility (see Table $3)$.

Finally, one hundred and one participants completed the PES and then the BSHS ( $\alpha=.72)$. The PES negatively correlated with state humility, $r(99)=-.55, p<.001$.

\section{State pride}

Two hundred and two participants completed both the BSHS and the state version of the Authentic/Hubristic Pride scales ( $\alpha=.74)$. Fourteen participants (6.9\%) failed the distraction probe and were not included $(n=188)$. Controlling for the other form of pride, hubristic pride negatively correlated with state humility, $r(185)=-.40, p<.001$, whereas authentic pride did not correlate with state humility $r(185)=-.05, p=.484$.

\section{Social desirability}

Three hundred and one participants completed the BSHS $(\alpha=.70)$ and the BIDR. Nineteen (6.3\%) failed the distraction probe, one participant had an extreme $z$-score $(z<-3.6)$, and were not included $(n=281)$. The BSHS did not correlate with either self-deceptive enhancement, $r(279)=-.03, p=.624$, or impression management, $r(279)=.09, p=.110$.

To ensure that this lack of correlation was not due to anchoring, we also recruited 98 participants to complete the BIDR on a 7-point scale. Eight (8.1\%) participants failed the distraction probe and were not included $(n=90)$. As before, the BSHS did not significantly 
Table 2. Correlations between the Brief State Humility Scale and the HEXACO subscales (Studies 2 and 3).

\begin{tabular}{|c|c|c|c|}
\hline & $\alpha$ & $r$ & $95 \% \mathrm{Cl}$ \\
\hline Honesty-Humility & .84 & $.49^{* * *}$ & {$[.39, .58]$} \\
\hline Sincerity & .74 & $.16^{*}$ & {$[.03, .28]$} \\
\hline Fairness & .85 & $.21^{* * *}$ & {$[.09, .33]$} \\
\hline Greed Avoidance & .80 & $.27^{* * *}$ & {$[.14, .38]$} \\
\hline Modesty $^{\ddagger}$ & .78 & $.78^{* * *}$ & {$[.75, .81]$} \\
\hline Emotionality & .86 & $.24^{* * *}$ & {$[.12, .36]$} \\
\hline Fearfulness & .69 & $.22^{* * *}$ & {$[.10, .34]$} \\
\hline Anxiety & .78 & $.19^{* *}$ & {$[.07, .31]$} \\
\hline Dependence & .78 & .05 & {$[-.07, .18]$} \\
\hline Sentimentality & .78 & $.24^{* * *}$ & {$[.12, .36]$} \\
\hline Extraversion & .89 & $-.11^{\dagger}$ & {$[-.23, .02]$} \\
\hline Social Self-esteem & .68 & $-.13^{\dagger}$ & {$[-.25, .00]$} \\
\hline Social Boldness & .76 & $-.15^{*}$ & {$[-.27,-.02]$} \\
\hline Sociability & .84 & .00 & {$[-.12, .13]$} \\
\hline Liveliness & .79 & -.09 & {$[-.21, .04]$} \\
\hline Agreeableness & .84 & .09 & {$[-.03, .21]$} \\
\hline Forgiveness & .79 & .02 & {$[-.11, .15]$} \\
\hline Gentleness & .73 & .10 & {$[-.03, .22]$} \\
\hline Flexibility & .54 & .09 & {$[-.04, .21]$} \\
\hline Patience & .75 & .07 & {$[-.06, .19]$} \\
\hline Conscientiousness & .82 & .09 & {$[-.04, .21]$} \\
\hline Organization & .74 & .03 & {$[-.09, .16]$} \\
\hline Diligence & .75 & $.13^{*}$ & {$[.00, .25]$} \\
\hline Perfectionism & .50 & .09 & {$[-.04, .21]$} \\
\hline Prudence & .62 & .02 & {$[-.11, .14]$} \\
\hline Openness & .81 & $.12^{\dagger}$ & {$[-.01, .24]$} \\
\hline Aesthetic Appreciation & .63 & $.20^{* *}$ & {$[.07, .31]$} \\
\hline Inquisitiveness & .67 & .03 & {$[-.10, .16]$} \\
\hline Creativity & .75 & -.01 & {$[-.14, .11]$} \\
\hline Unconventionality & .64 & $.14^{*}$ & {$[.01, .26]$} \\
\hline Altruism & .71 & $.47^{* * *}$ & {$[.36, .56]$} \\
\hline
\end{tabular}

${ }^{\dagger} p<.10 ;{ }^{*} p<.05 ;{ }^{* * *} p<.01 ;{ }^{* * *} p<.001 ;{ }^{\ddagger}$ Modesty subscale correlation includes all samples from Study $2 \mathrm{a}$ and $2 \mathrm{~b}(n=656)$. Significant correlations are in bold.

$95 \% \mathrm{Cl}=95 \%$ confidence interval.

correlate with self-deceptive enhancement, $r(88)=.01, p=.996$, or impression management, $r(88)=.08, p=.427$.

\section{Self-esteem}

Ninety-two participants first responded to the RSE $(\alpha=.87)$ and then the BSHS $(\alpha=.65)$. Three (3.2\%) participants failed the distraction probe and were excluded $(n=89)$. Contrary to expectations, no relationship was observed between self-esteem and humility, $r(87)=.03$, $p=.787$ - neither a linear $(\beta=.03, p=.765)$ or a quadratic one $(\beta=-.04, p=.722)$. Although these results were unexpected, they strengthen the discriminant validity of the BSHS.

\section{Discussion}

Supporting the convergent validity of our new measure, state humility strongly correlated with trait humility and negatively correlated with entitlement, hubristic pride, and two different measures of narcissism. Additionally, self-reported state humility correlated with 
Table 3. Correlations between the Brief State Humility Scale and Narcissism subscales (Study 2a).

\begin{tabular}{|c|c|c|c|}
\hline & $\alpha$ & $r$ & $95 \% \mathrm{Cl}$ \\
\hline $\mathrm{NPI}$ & .81 & $-.64^{* * *}$ & {$[-.74,-.50]$} \\
\hline Authority & .84 & $-.47^{* * *}$ & {$[-.60,-.30]$} \\
\hline Self-sufficiency & .50 & $-.52^{* * *}$ & {$[-.65,-.37]$} \\
\hline Superiority & .55 & $-.58^{* * *}$ & {$[-.70,-.43]$} \\
\hline Exhibitionism & .73 & $-.42^{* * *}$ & {$[-.57,-.24]$} \\
\hline Exploitativeness & .64 & $-.44^{* * *}$ & {$[-.58,-.27]$} \\
\hline Vanity & .78 & $-.30^{* *}$ & {$[-.47,-.11]$} \\
\hline Entitlement & .56 & $-.44^{* * *}$ & {$[-.58,-.27]$} \\
\hline PNI & .76 & $-.20^{*}$ & {$[-.38,-.00]$} \\
\hline Contingent Self-Esteem & .90 & .03 & {$[-.17, .23]$} \\
\hline Devaluing & .81 & -.11 & {$[-.30, .10]$} \\
\hline Entitlement Rage & .83 & $-.30^{* *}$ & {$[-.47,-.10]$} \\
\hline Exploitativeness & .83 & $-.34^{* * *}$ & {$[-.50,-.14]$} \\
\hline Grandiose Fantasy & .84 & -.15 & {$[-.34, .06]$} \\
\hline Hiding the Self & .76 & -.01 & {$[-.21, .19]$} \\
\hline Self-Sacrificing Self-Enhancement & .74 & .03 & {$[-.17, .23]$} \\
\hline
\end{tabular}

lay- and theory-defined observer-rated humility as elicited by theoretically-informed writing prompts. As evidence of its discriminant validity, state humility showed no correlation to self-esteem, authentic pride, or social desirability.

State humility's highest correlation with any measure was with the modesty subscale of HEXACO Honesty-Humility. In hindsight, this may not be surprising, as the modesty subscale includes four items that are similar to our operationalization of state humility (e.g. "I am an ordinary person who is no better than others" and "I wouldn't want people to treat me as though I were superior to them").

\section{Study 2 b: Differentiating humility and modesty}

We sought to extend the construct validation of Study 2 a by focusing on humility's complex relationship to modesty. We separate these studies from those of Study 2 a for two reasons. First, the structure of the studies that follow is different, as they include four scales per sample (i.e. BSHS, two modesty subscales, and one target construct) rather than just two (i.e. the BSHS and a target construct). Second, we propose that humility and modesty will show a complex and theoretically important pattern of convergence and divergence with our chosen criterion variables. Humility and modesty are closely related, but can demonstrate key differences in theoretically-relevant areas, such as moderating attention to the self (Davis et al., 2015). In light of the high correlation between the modesty subscale of the HEXACO and the BSHS, this study will both demonstrate incremental validity beyond the previous measures where appropriate, as well as illuminate how to theoretically disentangle these two constructs.

We examine the ability of the BSHS and both the HEXACO and IPIP (i.e. NEO) modesty subscales to predict four theoretically relevant constructs involving self-perception, other-perception, and group behavior - namely, the better-than-average effect (Guenther \& Alicke, 2010), the dark triad (i.e. narcissism, Machiavellianism, and psychopathy; Paulhus \& Williams, 2002), observer ratings of humility, and positive deviance (i.e. defiance of group 
cohesion and norms for the group's benefit; Spreitzer \& Sonenshein, 2004). As evidence of convergent validity, we predicted that humility and modesty are both indicated by less of a tendency to engage in normative self-inflation (i.e. the better-than-average effect) and a lack of narcissism.

However, humility and narcissism are not mere opposites of each other (Chancellor \& Lyubomirsky, 2013), and the relationship between the two constructs is at times complicated (e.g. they have even shown a positive interaction; Owens, Wallace, \& Waldman, 2015). As such, we do not seek to demonstrate incremental validity of the BSHS over the modesty subscales on narcissism. For example, it may be the case that modesty is the more natural opposite of narcissism than is humility. If humility and the dark triad are independent constructs, they may have a more complicated relationship than humility and narcissism as two ends of a single construct.

Psychologists have theorized that neutral, third-party judgments of a target's behavior in situations that highlight and reveal humility (e.g. responding to criticism, assigning credit for group successes), is acutely reflective of the way in which humility is used in common Western parlance (i.e. how laypersons describe the presence of lack of humility in others), and thus, a particularly good criterion variable for validating humility measurements (see the "gold standard" of humility in Chancellor \& Lyubomirsky, 2013). Although we expect both the BSHS and modesty subscales to correlate with observer judgments of a target's behavior in a humility-relevant situation, we expect that the BSHS will be the best predictor of this key criterion variable.

Positive deviance is highly relevant to both humility and modesty because it involves acting counter to group norms for positive, prosocial reasons, such as leaking classified documents to draw attention to governmental abuses of power. Humility is theoretically related to both a comparatively greater investment in the benefit of others and less investment in currying others' approval to bolster one's ego (Chancellor \& Lyubomirsky, 2013), whereas modesty is marked by its norm consciousness (Davis et al., 2015; Sedikides et al., 2008). As such, humility may be associated with a relatively lower likelihood of following norms when that deviance benefits the group; accordingly, we hypothesize that humility, not modesty, will predict positive deviance.

\section{Methods}

\section{Samples}

Similar to Study 2a, we employed multiple samples, and we report the respective sample sizes with each set of results. Unlike Study $2 a$, however, we included four measures per sample; the BSHS, the two modesty subscales, and one focal construct (described below).

\section{Measures}

To maintain consistency, the humility and modesty subscales were all reported on a scale of 1 (strongly disagree) to 7 (strongly agree). Order of presentation of the three scales was randomized.

Humility. Each subsample completed the BSHS (as ranged from .79 to .85). 
Modesty. All participants completed two modesty subscales. The IPIP Modesty subscale consists of 10 items (e.g. "Dislike talking about myself"; $\alpha$ s ranged from .78 to .83). The HEXACO Modesty subscale has four items (e.g. "I want people to know that I am an important person of high status," reverse-scored; $\alpha$ s ranged from .76 to .80).

Dark triad. One hundred and two participants completed the Dark Triad scale (Jonason \& Webster, 2010). This measure consists of 12 items, rated on a scale of 1 (strongly disagree) to 7 (strongly agree), that in turn comprise three subscales: narcissism $(\alpha=.77)$, Machiavellianism $(\alpha=.82)$, and psychopathy $(\alpha=.73)$.

Better-than-average effect. One hundred participants rated themselves on three socially desirable items (i.e. intelligent, charismatic, attractive) and three socially undesirable (i.e. boring, ignorant, fearful) compared to other mTurk workers on a scale of one (much less than the average mTurk worker) to nine (much more than the average mTurk worker).

Observer ratings. One hundred and two participants responded to an open-ended prompt about someone else's anger, as in Study 1, and then five judges (five male; $M_{\text {age }}=31.20$, $\left.S D_{\text {age }}=7.26\right)$ rated these responses on humility and arrogance $(\alpha=.82 ; I C C[2,1]=.32)$.

Positive deviance. One hundred and thirteen participants read a short vignette in which a group came to a flawed consensus. In particular, the vignette focused on the possibility that if the participant spoke up, they may be branded as "arrogant"; we wanted to know whether participants felt it was more important to enact humility but be seen as arrogant vs. act in a group-conforming way and avoid the label of arrogance. Participants then responded to three questions asking how important it was that they speak up (importance), how much they wanted to speak up (desire), and what the likelihood was that they would speak up (likelihood), rated on a scale of 1 (strongly disagree) to 7 (strongly agree).

\section{Results and discussion}

Unless otherwise noted, the continuous variables (e.g. the humility and modesty scales) were standardized and entered simultaneously into a linear regression predicting the focal variable. Across all samples in Studies $2 a$ and $2 b$, the BSHS correlated with both the HEXACO modesty subscale, fixed-effect $r=.78$ [95\% Cl: .75, .81], and IPIP modesty subscale, fixed-effect $r=.59$ [95\% Cl: .52, .65].

\section{Dark triad}

Unlike the other focal variables in Study $2 \mathrm{~b}$, the dark triad are considered traits; as such, in this sample, we examined whether they predict the BSHS and modesty subscales, controlling for the other dark triad traits in multiple regression. Narcissism, $\beta=-.24, p=.022$, and psychopathy, $\beta=-.35, p=.003$, but not Machiavellianism, $\beta=.15, p=.213$, significantly predicted state humility when estimated simultaneously. Similarly, when estimated simultaneously, only narcissism negatively predicted HEXACO modesty, $\beta=-.51, p>.001$; neither psychopathy, $\beta=-.18, p=.10$, nor Machiavellianism, $p=.464$ did. Finally, only narcissism predicted IPIP modesty, $\beta=-.46, p<.001$, but not psychopathy, $p=.448$, or Machiavellianism, $p=.891$. Bivariate correlations are displayed in Table 4. 
Table 4. Correlations between the dark triad, humility, and modesty (Study 2b).

\begin{tabular}{lcccccc}
\hline & DT-N & DT-P & DT-M & BSHS & IPIP & HXC \\
\hline DT-N & {$[.77]$} & & & & & \\
DT-P & .36 & {$[.82]$} & & & & \\
DT-M & .45 & .62 & {$[.73]$} & & & \\
BSHS & -.30 & -.35 & $-.17^{+}$ & {$[.84]$} & & \\
IPIP & -.48 & -.24 & -.24 & .64 & {$[.83]$} & \\
HXM & -.54 & -.31 & -.26 & .69 & .63 & {$[.76]$}
\end{tabular}

”DT-N and BSHS marginally significant $(p=.08)$; all others significant at $\alpha<.05$. DT-N = Dark Triad Narcissism. DT-P = Dark Triad Psychopathy. DT-M = Dark Triad Machiavallianism. BSHS = Brief State Humility Scale. IPIP = International Personality Item Pool, Modesty. HXM = HEXACO Modesty subscale. Numbers below diagonal = Bivariate correlations. Bracketed numbers on the diagonal $=$ Cronbach's $\alpha$.

These results provide evidence of convergent validity in that trait narcissism negatively predicted all three measures of humility and modesty. Notably, the psychopathy subscale also negatively predicted humility, even when controlling for narcissism (and vice versa). This relationship provides evidence that humility is not merely the lack of narcissism. We expect that empathetic and other-focused aspects of humility may explain this relationship to psychopathy that was not accounted for by narcissism, and could serve as a target for further research.

\section{Better-than-average effect}

Rating oneself better than average on desirable traits (and worse than average on undesirable traits) negatively correlated with the BSHS, $r=-.33, p<.001$, HEXACO modesty, $r=-.32$, $p<.001$, and IPIP modesty, $r=-.52, p<.001$. That is, both humble and modest individuals were less likely to manifest the better-than-average effect - inflating or deflating their self-assessments on desirable and undesirable traits, respectively.

We examined further whether humility and modesty predicted exceptionalism (i.e. the absolute deviation from the mid-point of the scale) and self-denigration (rating of oneself as less-than-average on all traits), which we operationalized as zeroing-out standardized scores above zero on all traits. For exceptionalism, both the BSHS, $\beta=-.36, p=.015$, and IPIP modesty, $\beta=-.40, p=.001$, predicted less absolute deviation from the mid-point, but HEXACO modesty did not, $\beta=.20, p=.223$. For less-than-average evaluations, only IPIP modesty predicted greater self-denigration, $\beta=-.26, p<.001$, whereas the BSHS, $\beta=0.06$, $p=.455$, and HEXACO modesty, $\beta=0.05, p=.576$, did not. The same results were found with a dichotomous split at the scale mid-point.

In sum, all three humility and modesty scales predicted less of a tendency to report being better-than-average on desirable traits (or worse-than-average on undesirable traits). When tested simultaneously, only the BSHS and the IPIP modesty scale predicted less exceptionalism, but the IPIP modesty subscale also predicted general self-denigration. In general, the IPIP modesty subscale seems to reflect a particularly self-effacing form of modesty because participants high on that scale were also more likely to rate themselves less-than-average regardless of the trait in question.

\section{Observer ratings of humility}

Observer ratings of humility correlated with the BSHS significantly, $r=.28, p=.004$, and with IPIP modesty, $r=.19, p=.061$, and HEXACO modesty, $r=.17, p=.095$, marginally. With all measures entered into linear regression, only the BSHS predicted observer ratings, $\beta=.39$, 
$p=.03$, whereas IPIP modesty, $\beta=.04, p=.783$, and HEXACO modesty, $\beta=-.15 ; p=.392$, did not. These results provide evidence that despite humility's high correlation with modesty, state humility is the best predictor of behavior that observers rate as manifesting humility, both individually (i.e. zero-order correlations) and when controlling for the two modesty subscales (i.e. when estimated simultaneously).

\section{Positive deviance}

The BSHS correlated with the perception of the importance of speaking up, $r=.19, p=.039$, and likelihood of speaking up, $r=.19 p=.047$; no other correlations were significant. When entered into a linear regression, the BSHS predicted the perception of the importance of speaking up in the vignette, $\beta=.39, p=.009$, and HEXACO modesty marginally predicted the opposite, $\beta=-.31, p=.054$. The IPIP subscale marginally predicted a desire to not speak up, $\beta=-.21, p=.086$. Similarly, in the linear regression, the BSHS predicted a perception that it was likely that the participant would speak up, $\beta=.48, p=.001$.

In line with our predictions about the divergence of humility and modesty, state humility predicted positive deviance in the form of both the importance and perceived likelihood of speaking up; however, it did not predict desire to speak up, implying that the deviance is due to a perceived situational or interpersonal demand, not an intrapersonal motivation. Neither modesty subscale strongly predicted positive deviance; if anything, they weakly supported quiet compliance with the group.

\section{Discussion of Study $2 b$}

Four constructs were presented that provided both convergent and discriminant validity for humility and modesty. Foremost, both humility and modesty were correlated negatively with narcissism, providing support that both are marked by a lack of toxic self-aggrandizement. Relatedly, all the scales predicted a relatively less inflated view of the self. However, humility and modesty have important differences that were revealed in our results. First, the manner in which the lack of self-inflation occurred differed by scale, with the BSHS predicting a moderate self-view (i.e. proximity to the mid-point of the scale) and the IPIP predicting both a moderate view but also a self-denigrating one (i.e. rating oneself below the mid-point/ worse-than-average - across both desirable and undesirable traits). Second, in line with our conception of humility, only the BSHS predicted positively deviant attitudes. Finally, state humility was the best predictor of observer-ratings of humility both with and without the inclusion of modesty subscales. Taken together, our results clarify the tightly linked relationship between state humility and modesty, and in particular the very high correlation between the BSHS and the HEXACO modesty subscale. These results align with recent research demonstrating a close association between the two constructs (Davis et al., 2015), while also finding additional evidence for differences in key theoretical areas, such as moderating attention to self and others' perception of humility. Although the two are highly correlated, they do diverge from one another in critical theoretically-meaningful ways.

\section{Study 3}

Having established that the BSHS demonstrates strong convergent validity with measures of closely related constructs such as narcissism and modesty, as well as no substantive 
correlation with social desirability or self-esteem, we turn to replicating and expanding the theoretical network of state humility. In our third study, we included prosocial variables (i.e. empathy, forgiveness, altruism) to demonstrate that state humility has a similar profile as trait humility. However, we also incorporated novel variables not previously explored in prior research to expand the theoretical bases of the construct. In particular, we included measures of intrapersonal constructs, such as openness, affect, and creativity. Predictions derived from prior research and theory are listed below.

\section{Gender and age}

In line with previous research that demonstrated women to be less narcissistic (e.g. Foster, Campbell, \&Twenge, 2003) and more humble (Lee \& Ashton, 2004) than men, we anticipated that women would report more humble feelings than men. Similarly, as previous research demonstrates a negative relationship between narcissism and age (e.g. Roberts, Edmonds, \& Grijalva, 2010; Twenge \& Foster, 2010), we anticipated a positive relationship between state humility and age.

\section{Affect}

We expected that state humility would correlate negatively with negative affect, but have no relationship with positive affect. Humility is theoretically related to a stronger sense of security and an open-minded acceptance of the realities regarding both the self and the world at large (Chancellor \& Lyubomirsky, 2013). As such, many traditional sources of anxiety, fear, and anger, such as concerns about one's own inadequacy, should be mitigated during humble moments. The expected relationship with positive affect was less theoretically clear. If low humility is associated with self-aggrandizement and entitled sensation-seeking (e.g. Emmons, 1981), then it should relate to some forms of high-arousal positive affect. However, high humility is also theoretically related to several low-arousal positive emotions, such as gratitude, awe, and contentment (Chancellor \& Lyubomirsky, 2013). As such, we predicted a complicated relationship that lacked a clear linear correlation with positive affect in general. We also conducted polynomial regressions, but did not have clear a priori predictions.

\section{Creativity}

We predicted that those in a humble state would be more cognitively open and flexible and therefore show more divergent thinking. We do not suggest that those experiencing humility are necessarily inherently more creative but rather that, as they have more realistic views of their abilities (Chancellor \& Lyubomirsky, 2013), they may avoid prematurely settling on a solution. They may be more open to multiple solutions and do not presume to immediately know the answer.

\section{Empathy}

We anticipated that those higher in empathy would be more likely to experience humble states because empathy involves a focus and awareness of others (Davis, 1983) and therefore 
a relatively low self-focus (Chancellor \& Lyubomirsky, 2013; Tangney, 2000). In particular, facets of empathy that focus on others, such as perspective-taking or concern for others' well-being, should be positively related to state humility.

\section{Forgiveness}

We predicted that those in a humble state would forgive more easily because they are more capable of imagining their own faults (Chancellor \& Lyubomirsky, 2013), which has been shown to increase forgiveness (Exline, Baumeister, Zell, Kraft, \&Witvliet, 2008), and because entitlement has been shown to obstruct forgiveness (Exline, Baumeister, Bushman, Campbell, \& Finkel, 2004).

\section{Personality}

As previously discussed, modest individuals are more likely to experience state humility. We also considered the other five higher-order personality traits in the HEXACO personality framework and their constituent lower-order traits. For reasons described earlier, we expected state humility to correlate positively with Altruism and Openness, and negatively with Emotionality. As the HEXACO is explicitly designed to capture humility-relevant aspects of Agreeableness and Conscientiousness as part of a separate Honesty-Humility factor (Ashton \& Lee, 2007), we did not expect state humility to significantly correlate with either trait. Finally, because narcissism is positively correlated with Extraversion in both self- and other-reports (e.g. Bradlee \& Emmons, 1992; Paulhus \& John, 1998), we expected a weak but negative relationship between state humility and Extraversion.

\section{Social dominance orientation}

Social dominance orientation involves a belief that some groups are inferior and others are superior (Pratto, Sidanius, Stallworth, \& Malle, 1994). As we propose that humility involves egalitarianism (Chancellor \& Lyubomirsky, 2013), in part because it entails an awareness of ones' own limitations and others' strengths, then those who believe in the inferiority of others due to group membership should be less likely to experience humility, because they are less likely to perceive their own limitations or to recognize the strengths of outgroup members.

\section{Method}

\section{Samples}

We paired each related construct with the BSHS in its own separate sample. The size of each subsample is reported along with each measure's results.

\section{Measures}

Positive Affect and Negative Affect Schedule. The Positive Affect and Negative Affect Schedule (PANAS; Watson et al., 1988) consists of 20 emotion words (e.g. "enthusiastic" and "guilty") rated on a scale of 1 (not at all) to 5 (extremely) that the participant is feeling at that moment. It consists of two subscales - positive $(\alpha=.90)$ and negative affect $(\alpha=.93)$. 
Modified Differential Emotions Scale. The modified Differential Emotions Scale (mDES; Fredrickson, Tugade, Waugh, \& Larkin, 2003) consists of 20 short statements that include three emotion adjectives (e.g. "I feel amused, fun-loving, silly" and "I feel angry, irritated, annoyed") to which participants respond on a scale of 0 (not at all) to four (extremely) how they feel at that moment. The items include 11 positive $(\alpha=.92)$ and nine negative $(\alpha=.93)$ discrete emotions.

Eight discrete emotions. In addition to the measures above, we included eight emotion items (i.e. amused, content, serene, happy, angry, sad, disgusted, anxious; adapted from Ekman, Freisen, \& Ancoli, 1980; Fredrickson \& Branigan, 2005) at the end of six of the batteries. Participants responded to these items on a scale of 1 (not at all) to 5 (extremely). We included these items as a tertiary measure with a larger sample than that used with the first two affect scales.

Creativity. The Remote Associates Test (RAT; Mednick \& Mednick, 1967) is a measure of divergent thinking. It consists of sets of three seemingly unrelated words (e.g. "walker,"'main," and "sweeper") whereby the respondent is asked to produce a fourth word that relates conceptually to all three (e.g. "street"). Participants completed 15 problems of medium difficulty without a time limit.

Empathy. The Davis (1983) Empathy scale consists of 28 items, scored on a scale of 1 (strongly disagree) to 5 (strongly agree), that comprise four subscales: Perspective-Taking (e.g. "I believe that there are two sides to every question and try to look at them both"; $\alpha=.73$ ), Empathic Concern (e.g. "When I see someone being taken advantage of, I feel kind of protective toward them"; $\alpha=.87$ ), Personal Distress ("I tend to lose control during emergencies"; $\alpha=.81$ ), and Fantasy (e.g. "I daydream and fantasize, with some regularity, about things that might happen to $\left.\mathrm{me}^{\prime \prime} ; \alpha=.77\right)$.

Forgiveness. The Transgression-Related Interpersonal Motivations Inventory (TRIM; McCullough et al., 1998) consists of 12 items, scored on a scale of 1 (strongly disagree) to 5 (strongly agree), that comprise two subscales: Revenge (e.g. "I'll make him/her pay"; $\alpha=.92$ ) and Avoidance (e.g. "I withdraw from him/her"; $\alpha=.95$ ). Participants were instructed to think about a person who had recently hurt them and to respond to the questions about that person.

Personality. See previous section for a description of HEXACO Honesty-Humility. The other five traits in the HEXACO are Emotionality (e.g. "I sometimes can't help worrying about little things"), Extraversion (e.g. "In social situations, I'm usually the one who makes the first move"), Agreeableness (e.g."I am usually quite flexible in my opinions when people disagree with me"), Conscientiousness (e.g. "I clean my office or home quite frequently"), and Openness (e.g. "I'm interested in learning about the history and politics of other countries"), as well as an additional interstitial trait, Altruism ("I try to give generously to those in need"). Each trait is comprised of four facets (except Altruism; see Lee \& Ashton, 2004 for a description of each facet).

Social dominance orientation. The Social Dominance Orientation scale (SDO; Pratto et al., 1994) comprises 14 items (e.g. "Some people are just inferior to others"; $\alpha=.90$ ) scored on a scale of 1 (very negative) to 7 (very positive). 


\section{Results and discussion}

\section{Gender and age}

Supporting our predictions, women reported greater state humility $(M=5.34, \mathrm{SD}=0.93$ ) than men $(M=4.86, \mathrm{SD}=1.03), t(2410)=12.07, p<.001, d=.49$. Furthermore, as expected, age correlated positively with state humility, $r(2235)=.14, p<.001$.

\section{Affect}

PANAS. Two hundred and fifty-three participants completed the BSHS ( $\alpha=.78)$ and then the PANAS (see Table 5). State humility correlated with low negative affect, $r(251)=-.29$, $p<.001$, and did not correlate with positive affect, $r(251)=-.09, p=.172$. Considering each negative emotion separately, state humility correlated negatively with all of them and most strongly with low hostility, $r(251)=-.34, p<.001$.

We also performed exploratory nonlinear analyses on the relationship between state humility and the PANAS. Negative affect maintained its negative linear relationship but positive affect demonstrated a positive quadratic term.

When the emotion items were analyzed individually, we found that all negative affect items conformed to the negative linear relationship. However, individual positive emotions showed a mix of linear and quadratic patterns (see Table 5). Items related to activity (i.e. strong, inspired, determined, active) demonstrated no linear relationship but a positive quadratic relationship (U-shape), whereas those related to attention (i.e. alert, attentive) demonstrated both a positive linear and positive quadratic (i.e. positive relationship that gets increasingly strong). Finally, those related to excitement (i.e. excited, enthusiastic) demonstrated a negative linear relationship.

mDES. Ninety-nine participants first responded to the BSHS $(\alpha=.83)$ and then to the mDES. We examined the results both in aggregate (combining all like-valenced emotions) and individually. As bivariate correlations, negative affect negatively related to state humility, $r(97)=-.25, p=.012$, and positive affect had no relationship, $r(97)=-.01, p=.915$. However, when analyzed as polynomial regressions, positive affect demonstrated a U-shaped relationship (linear $\beta=.03, p=.742$, quadratic $\beta=.37, p<.001$ ), indicating that both low and high humility were correlated with positive affect. Negative affect still demonstrated a linear negative relationship (linear $\beta=-.26, p=.009$, quadratic $\beta=-.10, p=.22$.)

Eight discrete emotions. Five hundred and twenty-two participants completed eight discrete emotion items directly after completing one of six other batteries. The pattern of results for these discrete emotions was the same as that found in the first two. At the bivariate level, positive affect demonstrated no relationship with state humility, $r(520)=-.07, p=.13$, whereas negative affect correlated negatively, $r(520)=-.10, p=.02$. However, when analyzed with a polynomial regression, positive affect had no linear relationship $(\beta=-.04, p=.396$ ), but did have a positive quadratic term $(\beta=.09, p=.012)$. Negative affect demonstrated only a linear negative term $(\beta=-.10, p=.022)$ and no quadratic term $(\beta=-.00, p=.929)$.

In sum, affect demonstrated a consistent set of relationships with humility across all three measures. As we anticipated, state humility related to low levels of negative affect. Future research can examine the causal direction of this relationship. For example, state humility may confer a sense of security and resilience that actively inhibits negative affect. Another 
Table 5. Affect as a function of State Humility (Study 3).

\begin{tabular}{|c|c|c|c|c|c|c|c|}
\hline \multirow[b]{2}{*}{ Outcome } & \multicolumn{2}{|c|}{ Model 1 (Linear term) } & \multicolumn{5}{|c|}{ Model 2 (Linear and quadratic terms) } \\
\hline & Linear $\beta$ & $R^{2}$ & Linear $\beta$ & Quadratic $\beta$ & $\Delta R^{2}$ & $R^{2}$ & Description \\
\hline Positive affect & -.09 & .01 & -.03 & $.15^{* *}$ & $.04^{* *}$ & $.05^{* *}$ & U-shape \\
\hline Attentive & $.12^{\dagger}$ & $.01^{\dagger}$ & $.17^{* *}$ & $.16^{* * *}$ & $.05^{* * *}$ & $.06^{* * *}$ & $\begin{array}{l}\text { Increasingly } \\
\text { positive }\end{array}$ \\
\hline Alert & .08 & .01 & $.11^{\dagger}$ & $.11^{*}$ & $.02^{*}$ & $.03 *$ & $\begin{array}{l}\text { Increasingly } \\
\text { positive }\end{array}$ \\
\hline Interested & .05 & .00 & .10 & $.15^{* *}$ & $.04^{* *}$ & $.04^{* *}$ & Positive \\
\hline Strong & -.10 & .01 & -.06 & $.13^{* *}$ & $.03^{* *}$ & $.04^{* *}$ & U-shape \\
\hline Inspired & $-.12^{\dagger}$ & $.01^{\dagger}$ & -.08 & $.11^{*}$ & $.02^{*}$ & $.03^{*}$ & U-shape \\
\hline Determined & -.01 & .00 & .02 & $.08^{*}$ & $.01^{\dagger}$ & .01 & U-shape \\
\hline Active & $-.13^{*}$ & $.02^{*}$ & -.10 & $.09^{\dagger}$ & $.01^{\dagger}$ & $.03^{*}$ & U-Shape \\
\hline Proud & $-.16^{* *}$ & $.03^{* *}$ & $-.11^{\dagger}$ & $.15^{* *}$ & $.04^{* *}$ & $.07^{* * *}$ & $\begin{array}{l}\text { Decreasingly } \\
\text { negative }\end{array}$ \\
\hline Excited & $-.18^{* *}$ & $.03^{* *}$ & $-.15^{*}$ & $.10^{*}$ & $.02^{*}$ & $.05^{* *}$ & $\begin{array}{l}\text { Decreasingly } \\
\text { negative }\end{array}$ \\
\hline Enthusiastic & $-.16^{*}$ & $.02^{*}$ & $-.13^{*}$ & .07 & .01 & $.03^{*}$ & Negative \\
\hline Negative affect & $-.29^{* * *}$ & $.08^{* * *}$ & $-.28^{* * *}$ & .03 & .01 & $.09 * * *$ & Negative \\
\hline Distressed & $-.23^{* * *}$ & $.06^{* * *}$ & -.24 & -.01 & .00 & $.06^{* * *}$ & Negative \\
\hline Upset & $-.17^{* *}$ & $.03^{* *}$ & $-.17^{*}$ & .01 & .00 & $.03^{*}$ & Negative \\
\hline Guilty & $-.22^{* * *}$ & $.05^{* * *}$ & $-.20^{* *}$ & .05 & .01 & $.06^{* * *}$ & Negative \\
\hline Scared & $-.26^{* * *}$ & $.07^{* * *}$ & $-.24^{* * *}$ & .06 & .01 & $.08^{* * *}$ & Negative \\
\hline Hostile & $-.34^{* * *}$ & $.11^{* * *}$ & $-.32^{* * *}$ & .03 & .00 & $.11^{* * *}$ & Negative \\
\hline Irritable & $-.20^{* *}$ & $.04^{* *}$ & $-.20 * *$ & .01 & .00 & .04 & Negative \\
\hline Ashamed & $-.26^{* * *}$ & $.07^{* * *}$ & $-.24^{* * *}$ & .05 & .00 & $.07^{* * *}$ & Negative \\
\hline Nervous & $-.25^{* * *}$ & $.06^{* * *}$ & $-.25^{* * *}$ & .00 & .00 & $.06^{* * *}$ & Negative \\
\hline Jittery & $-.18^{* *}$ & $.03^{* *}$ & $-.19^{* *}$ & -.03 & .00 & $.03^{*}$ & Negative \\
\hline Afraid & $-.19^{* *}$ & $.04^{* *}$ & $-.18^{* *}$ & .04 & .00 & $.04^{* *}$ & Negative \\
\hline
\end{tabular}

Notes: Model 1 included the linear term only. Model 2 included both the linear and the quadratic term. PANAS = Positive and Negative Affect Schedule.

${ }^{\dagger} p<.10 ;{ }^{*} p<.05 ;{ }^{* *} p<.01 ;{ }^{* *} p<.001$.

possible interpretation is that some individuals in a negative state become more self-protective as a coping mechanism and subsequently become more self-focused. Alternatively, a third variable, such as gratitude, may simultaneously increase both humility and decrease negative affect.

Additionally, as anticipated, positive affect did not initially appear to linearly relate to state humility. However, nonlinear exploratory analyses indicated that this lack of bivariate correlation concealed a more complex relationship. Specifically, positive affect was found to co-occur with both high and low state humility in a U-shaped curve. Although the presented polynomial regressions were exploratory, they were consistent across three different measures of affect in three different samples.

One possible interpretation of this pattern is that high and low humility relate to affect through different mediators. For example, with respect to the activity-relevant items of the PANAS, low humility may relate to exaggerated self-efficacy, which may relate to feelings of drive, whereas high humility may relate to strongly held values that may in turn inspire motivated behavior.

\section{Creativity}

One hundred and fifty-three participants first completed the BSHS $(\alpha=.74)$ and then 15 problems from the RAT. Twelve participants reported having previously completed the RAT items used in the study and were excluded prior to analysis, yielding a sample size of 141 . State humility predicted better performance on the RAT, $r(139)=.22, p=.008$ (see Table 6). 
Table 6. Correlations between Brief State Humility Scale and measures in Study 3.

\begin{tabular}{lccc}
\hline & df & $r$ & $p$ \\
\hline Empathy & 95 & & \\
$\quad$ Perspective-taking & & 0.2 & 0.047 \\
Empathic concern & & 0.21 & 0.036 \\
Fantasy & & 0.04 & 0.676 \\
Personal distress & & -0.02 & 0.859 \\
$\quad$ Creativity & 139 & 0.22 & 0.008 \\
Forgiveness & & -0.28 & 0.003 \\
$\quad$ Revenge & 109 & -0.13 & 0.159 \\
Avoidance & 109 & -0.58 & 0.001 \\
Social dominance orientation & 100 & & \\
\hline
\end{tabular}

Note: Blank spaces have an equal value to the cell above them.

As expected, state humility correlated with creativity as measured by performance on the RAT, which requires broad thinking to discover connections between sets of seemingly unconnected words. State humility may aid in cognitive tasks that require broad, flexible thinking because it reflects an open mindset or because a "quiet ego" that has disappeared into one's psychological background does not intrude on the task at hand (Exline, 2008).

\section{Empathy}

One hundred and three participants first responded to the BSHS ( $\alpha=.73)$ and then completed the Davis Empathy scale. Six (5\%) failed the distraction probe and were excluded $(n=97)$. State humility related to perspective-taking, $r(95)=.20, p=.047$, and empathic concern, $r(95)=.21, p=.036$, but not to fantasy, $r(95)=.04, p=.676$, or personal distress, $r(95)=-.02, p=.859$ (see Table 6).

State humility's pattern of correlations with empathy was consistent with our reasoning. Humility was associated with aspects of empathy that reflected a concern and awareness of others (e.g. perspective-taking and empathic concern), but not with unrelated constructs such as fantasy or personal distress. Further research could explore whether frequent humble moments are a cause or consequence of a concern for others or the ability to take another individual's perspective. Furthermore, state humility may moderate the efficacy of empathy-based interventions, such that those experiencing humility may find it easier to be empathetic.

\section{Forgiveness}

One hundred and eleven participants first responded to the BSHS $(\alpha=.73)$ and then completed the TRIM. State humility predicted less desire for revenge, $r(109)=-.28, p=.003$, but did not significantly predict avoidance, $r(109)=-.13, p=.159$ (see Table 6). Controlling for each TRIM subscale, state humility still negatively predicted revenge, $r(108)=-.25, p=.009$, but demonstrated no relationship with avoidance, $r(108)=.01, p=.96$.

As suggested by prior studies of trait humility, state humility correlated with less desire for revenge. Reflecting both security (Kruse, Chancellor, \& Lyubomirsky, 2015) and empathy (see above), humble people are less motivated to "pay back" transgressions. However, as state humility did not correlate with avoidance, humble people may either engage or avoid transgressors. Future research may explore potential moderators of this effect. For example, beliefs about the outcomes of engagement may influence the response: During humble moments, people may engage transgressors when they feel they can fruitfully communicate with them (e.g. explain how the act was hurtful) and avoid them when they do not (e.g. believe the other will escalate the discussion to an unnecessary conflict). 


\section{Personality}

Two hundred and sixty-three participants completed the HEXACO measure (Lee \& Ashton, 2004; see Table 2 for alphas) and then the BSHS ( $\alpha=.85)$. Correlations are presented in Table 2. As expected, state humility positively correlated with Altruism and negatively with Extraversion (particularly, Social Boldness). Humility also marginally correlated with Openness and significantly with the facets Unconventionality and Aesthetic Appreciation. Surprisingly, state humility correlated positively with Emotionality. Finally, it did not correlate with Agreeableness or Conscientiousness. Although this lack of relationship may seem surprising, it may be due to the fact that the personality measure used, HEXACO, was specifically created to extract the aspects of Agreeableness and Conscientiousness relevant to Humility into its own trait (as well as the interstitial trait, Altruism).

Consistent with expectations, state humility was found to be related to openness and, in particular, the facets of aesthetic appreciation and unconventionality. One possibility is that aesthetic experiences reduce focus on the self, such as in experiences of awe (Chancellor \& Lyubomirsky, 2013), and subsequently boost feelings of humility in the short term. Additionally, its relationship with unconventionality may differentiate state humility from modesty. If modesty involves not drawing undue attention to oneself, the modest may be more likely to adopt conventional behaviors and thoughts to avoid attention (Cialdini et al., 1998), whereas the humble may be more likely to authentically express their identity even when it is non-normative. Additionally, the relationship with unconventionality may be culture-specific; in a society like the U.S. that values self-promotion (e.g. Kitayama, Markus, Matsumoto, \& Norasakkunkit, 1997), some level of deviance from the cultural norm may be necessary to be humble. As a final note, the creativity facet did not correlate significantly with state humility - a finding that seems to contradict the relationship between humility and the RAT. However, this discrepancy may reflect the difference between self-reported creativity (i.e. seeing oneself as creative) and actual creative behavior (see also Goncalo, Flynn, \& Kim, 2010, for findings of a link between self-reported creativity and narcissism).

Lastly, contrary to expectations, state humility correlated positively with Emotionality, including positive facets such as sentimentality and negative affective facets such as fearfulness and anxiety. At high levels of sentimentality, individuals report strong and close relationships with others, which is consistent with our conceptualization of state humility. However, associations with fearfulness and anxiety would appear incongruent with earlier results, which found state humility to be negatively correlated with state negative affect. However, state humility may relate to state and trait affect differently. For example, if state humility can buffer against negative affect by decreasing ego-threat, then individuals high in trait negative affect may use humility, or humility-eliciting processes such as gratitude, as a coping mechanism to mitigate their tendency to experience negative affect. Alternatively, some of the items on both subscales could be interpreted as socially undesirable but honest admissions of one's imperfections, which a humble person may be relatively more likely to endorse (e.g. "I sometimes can't help worrying about the little things" and "When it comes to physical danger, I am very fearful"). Other items are explicitly comparative (e.g. "I worry a lot less than most people do") or could be construed as boastful ("I don't mind doing jobs that involve dangerous work"). Viewed in this light, feelings of humility are not likely to be compatible with such self-statements.

Replicating prior findings regarding the relationship between humility and prosocial behavior (e.g. Exline \& Hill, 2012), altruism predicted state humility. This result reinforces the 
notion that state humility has a similar theoretical network as trait humility. Furthermore, humility is often proposed to precede prosociality (Hilbig \& Zettler, 2009; LaBouff et al., 2012), yet the correlation between trait altruism and state humility implies that prosociality may at times precede humility and, as such, this relationship may sometimes be mutually reinforcing. Experiencing an other-focused state - as when one is acting altruistically - may increase state humility, which, in turn, drives more prosocial behavior, and so on.

\section{Social dominance orientation}

One hundred and twelve participants first responded to the BSHS $(\alpha=.74)$ and then the SDO. Ten (8.9\%) failed the distraction probe were excluded $(n=102)$. As shown in Table 6, social dominance orientation negatively predicted state humility, $r(100)=-.58, p<.001$.

Supporting our predictions, we obtained evidence indicating that feelings of humility are associated with believing in equality among groups and equal treatment of others. This finding suggests a number of promising research directions. First, eliciting egalitarian attitudes may increase state humility. Second, state humility may moderate or mitigate discriminatory behavior. For example, the humble may be less likely to avoid individuals from stigmatized groups or to unfairly punish disenfranchised individuals.

\section{Study 4}

Our state approach enables experimental research on humility and, hence, exploration of humility's causes and outcomes. In a set of experiments, we manipulated two psychological processes that previously have been shown to increase observer ratings of humility - self-affirmation (Kruse et al., 2015) and gratitude (Kruse et al., 2014) - to test whether our new BSHS is sensitive to these manipulations. In addition to implementing these two manipulations to increase humility, we also attempted to decrease state humility by eliciting hubristic pride, and to test whether our measure is sensitive to that decrease. Taken together, Study 4 had three objectives: first, to validate the state-like nature of the BSHS by testing its sensitivity to manipulation; second, to test its construct validity by replicating previously observed effects on humility; and third, to explore a novel theoretical relationship with hubristic pride, a self-focused construct.

\section{Experimental Sample A: Self-affirmation}

Self-affirmation was expected to elevate humility because self-affirmation bolsters the self-concept and buffers against threat (see Kruse et al., 2014, for further details and theoretical motivation). When individuals are exposed to negative ego-threatening self-information, affirmed individuals are theoretically more able than others to accept their limitations. As such, a finding that self-affirmation increases humility supports a model in which humility is related to a secure identity and contradicts one in which humility is related to self-devaluing.

\section{Method}

Seventy-four participants completed either a values affirmation or control task. All participants first picked their highest and lowest value from a list of 14 common values (e.g. creativity, independence, relationships; adapted from Cohen, Aronson, \& Steele, 2000; Harris \& 
Napper, 2005). Participants in the values affirmation condition then wrote about the value they rated highest and why it is important to them. Participants in the neutral condition wrote about the value they rated lowest and why it might be important to someone else. Participants then responded to a short open-ended question about how they would respond if someone was angry with them; prior research has demonstrated that participants must be exposed to potentially ego-threatening self-information (e.g. their ability to transgress against others) for self-affirmation to increase humility (Kruse et al., 2015). Finally, participants completed the BSHS $(\alpha=.79)$.

\section{Results and discussion}

As expected, participants in the values-affirmation condition reported higher state humility $(M=5.39, \mathrm{SD}=.99)$ than those in the neutral control condition $(M=4.87, \mathrm{SD}=1.02)$, $t(72)=2.22, p=.029, d=.52$. These results replicate prior findings (Kruse et al., 2015), show that a brief task can elicit humble feelings, and provide evidence that the BSHS can serve as an acceptable manipulation check for a self-oriented manipulation.

\section{Experimental Sample B: Gratitude}

Gratitude is expected to increase humility by drawing attention to the strengths and contributions of others (for further discussion and theory motivating this study, see Kruse et al., 2014). This shift in focus to others should subsequently decrease self-focus and, as such, increase humility. Evidence that gratitude increases humility supports a model in which high other-focus and low self-focus are significant components of humility and, in turn, challenges a model in which self-devaluing is the core aspect of humility.

\section{Method}

Sixty-six participants either wrote a letter of gratitude or responded to a neutral prompt (i.e. described what they did during the $2 \mathrm{~h}$ before the study; Lyubomirsky, Dickerhoof, Boehm, \& Sheldon, 2011; see also Seligman, Steen, Park, \& Peterson, 2005). Participants then completed the BSHS $(\alpha=.86)$, as well as a manipulation check for gratitude (Gratitude Questionnaire-6; McCullough, Emmons, \& Tsang, 2002; $\alpha=.78$ ).

\section{Results and discussion}

The experimental elicitation was successful, with participants who wrote a letter of gratitude reporting higher levels of gratitude $(M=6.06, S D=0.85)$ than those in the neutral control condition $(M=5.64, \mathrm{SD}=0.85), t(64)=2.00, p=.049, d=.51$. As expected, the gratitude group reported higher state humility $(M=5.54, S D=1.07)$ than the neutral control group $(M=4.91, \mathrm{SD}=1.25), t(64)=2.19, p=.032, d=.55$. As with self-affirmation, these results replicate prior research (Kruse et al., 2014), demonstrate that humility can be manipulated (i.e. can be state-like), and again indicate that the BSHS can act as a responsive indicator of humility in studies testing other-oriented manipulations.

\section{Experimental Sample C: Hubristic pride}

Having demonstrated that humility, as measured by the BSHS, can be increased, we next turned to whether it can be decreased. We propose that hubristic pride should lower humility 
because it increases focus on oneself and one's superiority (Tracy \& Robins, 2007). Furthermore, hubristic pride and state humility are negatively correlated (see Study 2a). Although humility and authentic pride showed no relationship in Study 2a, we included the authentic pride subscale as an exploratory measure, without strong expectations for how it should interact with humility. Because the pride measure includes two aspects of pride, which we expected to have distinct relationships with humility, the analyses in this sample were more complicated than those in the previous samples.

\section{Method}

One-hundred twenty-three participants responded to either a hubristic pride manipulation (i.e. recalling a time when one "behaved in a self-important manner, or felt pretentious or stuck-up") or a neutral prompt (adapted from Ashton-James \& Tracy, 2012; see Appendix 2). All participants completed the state pride measure (containing both hubristic $[\alpha=.95]$ and authentic pride $[\alpha=.95])$ as a manipulation check and then completed the BSHS ( $\alpha=.83)$.

\section{Results and discussion}

As expected, the manipulation increased hubristic pride, $t(121)=2.94, p=.004, d=0.55$; however, it also marginally increased authentic pride, $t(121)=1.97, p=.051, d=0.37$. We regressed state humility on condition and both kinds of pride. Condition was effect-coded (i.e. a weight of 1 was assigned to the treatment condition and -1 to the control) and all the variables were standardized prior to inclusion. The main effects of authentic and hubristic pride were very similar to the correlations between pride and state humility observed previously (see Table 7, Step 1). Including interactions with condition significantly improved the model; although the two types of pride did not significantly predict state humility in the neutral condition, for participants in the pride condition, authentic pride positively predicted humility, $\beta=.21, p<.001$, and hubristic pride negatively predicted humility, $\beta=-.25, p<.001$ (see Table 7, Step 2). Additional interaction terms (e.g. authentic pride by hubristic pride) were not significant and their inclusion did not improve the model fit.

We conducted simple slopes analyses to elucidate the interactions. Hubristic pride did not significantly predict state humility in the neutral condition $(\beta=-.16, \mathrm{SE}=.16, p=.33)$, but did in the experimental condition $(\beta=-.66, \mathrm{SE}=.15, p<.001)$. By contrast, authentic pride marginally and negatively predicted state humility in the neutral condition $(\beta=-.22$, $\mathrm{SE}=.12, p=.078)$, and marginally and positively predicted state humility in the experimental condition $(\beta=.21, \mathrm{SE}=.12, p=.092)$.

In sum, our third experimental study replicated state humility's relationship to state pride from Study 2, while also showing that state humility can be undermined by the induction of hubristic pride. Furthermore, participants who responded to the hubristic pride manipulation with authentic pride (e.g. chose to write about a time they felt successful rather than superior) demonstrated an increase in state humility, controlling for hubristic pride.

To sum up, it appears that state pride has a complicated but consistent relationship with humility. Correlationally, humility is negatively related to hubristic pride and unrelated to authentic pride. This relationship was observed in both the construct validity study (Study 2a) and in the neutral condition of the current pride experiment (Study 4c). However, when pride was experimentally elicited, those who felt authentic pride showed increases in state humility and those who felt hubristic pride showed decreases. One implication of these results is that, as humility was more relevant for participants in pride states rather than those 
Table 7. State humility as a function of condition and pride (Experimental) (Study 4c).

\begin{tabular}{|c|c|c|}
\hline & $\Delta \Delta R^{2}$ & B \\
\hline Step 1 & $.23^{* * *}$ & \\
\hline Condition & & .12 \\
\hline Authentic pride & & -.01 \\
\hline Hubristic pride & & $-.49 * * *$ \\
\hline Step 2 & $.08^{* * *}$ & \\
\hline Condition & & .10 \\
\hline Authentic pride & & -.01 \\
\hline Hubristic pride & & $-.41^{* * *}$ \\
\hline Condition $\times$ Authentic pride & & $.22 * *$ \\
\hline Condition $\times$ Hubristic pride & & $-.27^{* *}$ \\
\hline Authentic pride $\times$ Hubristic pride & & -.06 \\
\hline Step 3 & .00 & \\
\hline Condition & & .11 \\
\hline Authentic pride & & -.00 \\
\hline Hubristic pride & & $-.41^{* * *}$ \\
\hline Condition $\times$ Authentic pride & & $.21^{*}$ \\
\hline Condition $\times$ Hubristic pride & & $-.25^{*}$ \\
\hline Authentic pride $\times$ Hubristic pride & & -.06 \\
\hline Condition $\times$ Hubristic pride $\times$ Authentic pride & & -.03 \\
\hline Total $R^{2}$ & .31 & \\
\hline$n$ & 123 & \\
\hline
\end{tabular}

in neutral states, it may be important to how individuals enter those states. Because humility is theoretically related to a realistic understanding of one's strengths and weaknesses (Chancellor \& Lyubomirsky, 2013; Tangney, 2000), researchers may want to explore whether it may "filter" appraisal of pride-eliciting scenarios, causing an increase in authentic pride and a decrease in hubristic pride. Humble individuals may reinterpret hubris-eliciting situations in more authentically-proud ways, even when hubris is explicitly appropriate, as in the present pride experiment.

\section{General discussion}

Across 25 samples and 2622 participants, we validated a novel self-report measure of humility with self- and other-ratings and extended the construct's theoretical network. The samples were broadly representative of the adult U.S. population in age, ethnicity, and education. We provide evidence for convergence and discrimination with related constructs (e.g. modesty and pride) and replicate the previously known relationships between humility and theoretically-related constructs (e.g. altruism and empathy). Of these constructs, humility demonstrated a theoretically interesting pattern of overlap and divergence with modesty. Notably, the BSHS was also not found to be significantly associated with either form of social desirability. The lack of relationship between our measure and social desirability is a major strength of the present measure, in light of consistent positive links found between prior humility measures and social desirability (e.g. Rowatt et al., 2006).

From a methodological perspective, the BSHS facilitates new avenues in at least three research contexts. First, by revealing ways that humble states can be evoked and undermined, our three experimental studies demonstrated that the measure is responsive to experimental change and therefore may be used as a dependent variable or a manipulation check for plausible humility-inducing inductions in theoretically novel paradigms. The BSHS 
can be used alone, as the only direct measure of humility, or can complement other measures of humility, such as other-report. Second, our new scale enables researchers to explore whether state humility may be a moderator of other states that are relevant to a "quiet ego." For example, if humility involves a greater openness and attention to the world, as indicated by the PANAS correlations, it may facilitate the experience of flow (Csikszentmihalyi, 1997). Third, our measure can enable research with multiple time points, thus allowing study of its role as trigger, mediator, or consequence of any number of emotional, motivational, or cognitive variables. For example, collecting other-reports of participants' humility every day over 3 weeks is difficult (i.e. three judges responding every day rather than one participant) and of questionable validity (e.g. raising questions about whether the judges interacted with the target participant each day and whether they can perceive subtle fluctuations in humility in the short term). As such, the BSHS complements existing measures and makes novel research directions possible.

Beyond validating a self-report measure of humility, we also sought to extend the theoretical structure of state humility correlationally and experimentally. Prior research on trait humility has focused mostly on correlations with beneficial interpersonal outcomes, and we replicated these relationships (i.e. with empathy, forgiveness, altruism). However, we also demonstrated novel relationships with intrapersonal constructs, such affect and creativity, and focused attention on understanding humility's potential triggers (e.g. gratitude and self-affirmation) and inhibitors (e.g. hubristic pride). Taken together, these findings provide evidence that feelings of humility are indicative of well-being and healthy functioning (Exline \& Geyer, 2004) and, depending on the causal direction of these relationships, engendering a state of humility may have benefits for the individual as well as the community.

\section{Proposed framework of humility}

Our results are consistent with the perspective that humility is a form of low self-focus (e.g. Leary \& Guadagno, 2011). When individuals are less focused on themselves, they are better able to focus not just on other people, but on the world around them. This outward shift in perspective could explain humble individuals' greater openness, engagement, and even creative problem solving. Low self-focus has been described as a core part of many theoretical definitions of humility (e.g. Chancellor \& Lyubomirsky, 2013; Exline, 2008; Tangney, 2000).

However, a pure low self-focus perspective does not fully explain these results. For example, in the self-affirmation study, thinking about the self actually increased humility. Indeed, we speculate that shifts in humility may often be preceded by brief increases in self-focus (i.e. introspection), as people re-examine what they know about themselves. Furthermore, although gratitude reliably boosts humility, it is unclear whether gratitude is more other-focused than many other emotions, such as anger. For example, both anger and gratitude often hinge on an action from another person (Smith \& Ellsworth, 1985). If humility merely involves the redirection of focus away from the self, then gratitude should be no more humbling than anger. However, as evidenced in the present studies, anger and humility are negatively related. Therefore, more refinement of the concept of "self/other focus" is needed.

Building on the results derived from our consensual definition of humility, one novel framework of humility involves resource investment (e.g. Hobfoll, 2002). In other words, humility may be conceptualized as an investment strategy for psychological resources. Rather than merely attending outside the self, the individual is proferring cognitive and social 
resources into the world and his or her relationships. In addition to explaining the same findings as the "other-focus" model, this approach offers a more nuanced understanding of what should and should not elicit humility and its downstream outcomes. For example, self-affirmation may increase focus on the self, but it shifts resources into an expanded definition of the self (such as one's values). Anger entails investment in egoic resources, like triumph and conquest, but gratitude involves investment in non-egoic resources, like relationships. Subsequently, as resources are diverted away from the self, they are more available to be deployed in other domains, such as attentiveness and problem solving.

We built this framework of humility out of the network of relationships observed in the present samples. Notably, we do not contend that this framework is reflected in our measure's items, but rather in the observed correlations and experimental shifts of those items. As discussed previously, the items on the BSHS are designed to be indirect and, as such, do not directly reflect either the underlying phenomenon or the theoretical framework. Indeed, we propose that the relatively striking and distal nature of the observed relationships suggests promising new avenues of research. For example, how does an item like "I feel that, overall, I am no better or worse than the average person" yield the observed pattern of results on emotions, engagement, or problem solving? We hope additional research to address this question.

\section{Limitations}

One potential limitation of our research is the overlap observed between our samples. A small collection of repeat participants may have biased the samples toward their idiosyncratic characteristics. However, although some overlap occurred, the majority of each of the samples was independent. Unlike studies in which a single sample of participants completes a lengthy battery of measures, we demonstrated largely independent correlations between humility and the related variables. Thus, the overlap in participants between correlations in the present samples was actually smaller than typically reported in similar scale validation studies. Our study samples were drawn from the U.S. and, with two exceptions, comprised online participants. Online samples necessarily involve less control than samples collected in a laboratory setting. Although critics may view online samples as potentially taking their participation less seriously - and be more distracted - than other types of samples, we believe they are a huge improvement over undergraduate samples, due to their representativeness and interest (rather than requirement) to participate. Furthermore, our use of distraction probes mitigated some concerns by providing a criterion for screening participants who were not attending to the instructions. That said, the use of more diverse samples and cross-cultural samples in the future will be critical to advance understanding of humility. For example, given the greater importance of social harmony in collectivist than in individualist cultures, members of collectivist cultures may place greater emphasis on adherence to social norms and, subsequently, may more closely conflate humility with the norm-conscious construct of modesty.

An additional limitation is that our measure does not attempt to test or assess whether humility has lower-level facets. The goal of this project was to create a brief measure and additional complexity was sacrificed in favor of simplicity. We encourage the development of longer measures of humility that fully address its complicated nature and complement our work. 
The BSHS demonstrated a strong correlation with the modesty subscale of the HEXACO personality inventory. On cursory examination, this relationship would seem to undermine the utility of the BSHS if it is redundant with existing methods. However, the constructs of modesty and humility are themselves closely related but distinct in two key ways (Chancellor \& Lyubomirsky, 2013; Sedikides et al., 2008). First, modesty is a behavioral style that avoids self-aggrandizement whereas humility is an internal cognitive state that is reflected in specific kinds of cognitions pertaining to the self. Thus, modesty is likely to be strongly culturally-dependent (i.e. cultures vary in what they consider modest behavior), whereas our conceptualization of humility may be differentially expressed in behavioral scripts across cultures. Second, humility reflects a highly balanced self-concept that resists both overly positive (i.e. better than others) and negative (i.e. worse than others) self-views. Modesty, however, reflecting a highly norm-conscious avoidance of attention, tends to simply reflect behaviors that avoid placing oneself above others.

These differences are revealed in the items of the scales themselves. In terms of behaviors, four of the ten items in the IPIP modesty subscale mention specific behaviors (e.g. "boast about my virtues," "myself the center of attention"). Only four of the IPIP modesty items pertain specifically to cognitions (e.g. "I have a high opinion of myself"), whereas all of the BSHS items reference cognitions (e.g. "I feel I have both many strengths and flaws"). Likewise, both BSHS item 4 and HEXACO modesty item 5 involve one's sense of superiority, but the BSHS items asks whether participants actually think they are better than most people and the modesty subscale asks whether participants want others to treat them as though they are superior. Relatedly, the BSHS asks whether the participant deserves more respect and the HEXACO modesty asks whether the participant wants "people to know that I am an important person." In both cases, modesty involves the avoidance of the outward (and behaviorally-manifested) appearance of superiority, whereas humility involves the actual internal (and cognitively-manifested) avoidance of superiority. Finally, in terms of self-views, HEXACO modesty items reflect only the avoidance of putting oneself above others (e.g. "no better than others," "more respect than the average person," "high status"). BSHS items, however, reflect an avoidance of both extremes (e.g." "no better or worse than others," "many strengths and flaws").

These differences, in turn, play out in the observed relationships. As discussed in Study $2 \mathrm{~b}$, both the HEXACO modesty subscale and the BSHS are similar in that they both correlated negatively with narcissism and exaggerated self-descriptions. However, state humility reflected the avoidance of both extremes, whereas modesty at times was associated with a general sense of being worse-than-average. Likewise, only state humility predicted positive deviance, whereas neither modesty subscale predicted acting against the groups' expectations. Lastly, the BSHS was the best predictor of observer ratings of humility, when estimated on its own and when controlling for the modesty subscales.

\section{Conclusion and future directions}

One of the primary goals of this paper was to open the door for further research. In particular, we hope that the introduction of our new measure, along with the construct of state humility, can jumpstart new experimental research on humility. Several unanswered questions remain about the nature of state humility or humble feelings. In particular, future investigators could attempt to map the relationship between state and trait humility. An individual's levels of 
trait humility may influence and anchor his levels of state humility, and repeated experiences of state humility may cause incremental shifts in trait humility across time. For example, humility-congruent worldviews and beliefs may systematically impact appraisal of situations (e.g. Scherer, 1997; Tomaka \& Blascovich, 1994) that may, in turn, influence whether individuals experience the situations as humbling or aggrandizing, and this process may cause dispositional humility to grow.

Another unanswered question concerns how state humility may vary cross-culturally in its mean levels, functionality (i.e. how it works), and the degree to which it is valued. We hypothesize that a nation's commitment to egalitarianism (Hofstede, 2001) will be positively correlated with mean levels of its residents' humble feelings. Likewise, nations with greater power distance and higher individualism (Schwartz, 1994) might be characterized by lower mean levels of state humility. Finally, although we suspect that the facilitative effects of self-affirmation and gratitude on state humility reflect general cognitive and affective processes, researchers should test that these results generalize to other cultures.

We hope that the novel relationships presented here inspire further research on humility and its intrapersonal dynamics, such as whether humility has hedonic benefits, whether it plays a role in overall success and well-being, and what are its potential drawbacks and limitations. For example, state humility may have favorable (and surprising) outcomes worth investigating. Although indicators of self-focus and narcissism appear to be growing in Western societies (Twenge \& Campbell, 2009), the study of state humility may help psychologists identify the moment-to-moment building blocks that lead to a more "self-less" and fulfilling life. Understanding how humility may be gained and lost may illuminate how people mature, navigate relationships and careers, and flourish across the course of their lives.

\section{Notes}

1. This total does not include undergraduates in Sample 1c in Study 1. Also, it does not include samples of raters used in Study 2.

2. Overlap between subsamples allowed assessing test-retest reliability across time. See Sample $1 d$ in Study.

\section{Disclosure statement}

No potential conflict of interest was reported by the authors.

\section{Funding}

This work was supported by the John Templeton Foundation [grant number \#21414].

\section{References}

Ashton, M. C., \& Lee, K. (2007). Empirical, theoretical, and practical advantages of the HEXACO model of personality structure. Personality and Social Psychology Review, 11, 150-166.

Ashton, M. C., \& Lee, K. (2008). The prediction of honesty-humility-related criteria by the HEXACO and five-factor models of personality. Journal of Research in Personality, 42, 1216-1228.

Ashton-James, C. E., \& Tracy, J. L. (2012). Pride and prejudice: How feelings about the self influence judgments of others. Personality and Social Psychology Bulletin, 38, 466-476. 
Baumeister, R. F., Smart, L., \& Boden, J. M. (1996). Relation of threatened egotism to violence and aggression: The dark side of high self-esteem. Psychological Review, 103, 5-33.

Borsboom, D., Mellenbergh, G. J., \& van Heerden, J. (2004). The concept of validity. Psychological Review, $111,1061-1071$.

Bradlee, P. M., \& Emmons, R. A. (1992). Locating narcissism within the interpersonal circumplex and the five-factor model. Personality and Individual Differences, 13, 821-830.

Buhrmester, M., Kwang, T., \& Gosling, S. D. (2011). Amazon's mechanical turk: A new source of inexpensive, yet high-quality, data? Perspectives on Psychological Science, 6, 3-5.

Campbell, W. K., Bonacci, A. M., Shelton, J., Exline, J. J., \& Bushman, B. J. (2004). Psychological entitlement: Interpersonal consequences and validation of a self-report measure. Journal of Personality Assessment, $83,29-45$.

Chancellor, J., \& Lyubomirsky, S. (2013). Humble beginnings: Current trends, state perspectives, and humility hallmarks. Social and Personality Psychology Compass, 7, 819-833.

Chancellor, J., Bao, J. K., \& Lyubomirsky, S. (2014). The propagation of everyday generosity in the workplace: The reinforcing benefits of giving, getting, and glimpsing. Manuscript submitted for publication.

Chancellor, J., Cornick, J., Nelson, S. K., Blascovich, B., \& Lyubomirsky, S. (2016). Above the Pale Blue Dot: Awe and state humility in immersive virtual environments. Manuscript submitted for publication.

Cialdini, R. B., Wosinska, W., Dabul, A. J., Whetstone-Dion, R., \& Heszen, I. (1998). When social role salience leads to social role rejection: Modest self-presentation among women and men in two cultures. Personality and Social Psychology Bulletin, 24, 473-481.

Cohen, G. L., Aronson, J., \& Steele, C. M. (2000). When beliefs yield to evidence: Reducing biased evaluation by affirming the self. Personality and Social Psychology Bulletin, 26, 1151-1164.

Cronbach, L. J., \& Meehl, P. E. (1955). Construct validity in psychological tests. Psychological Bulletin, 52, 281.

Csikszentmihalyi, M. (1997). Finding flow: The psychology of engagement with everyday life. New York, NY: Basic Books.

Dahlsgaard, K., Peterson, C., \& Seligman, M. E. (2005). Shared virtue: The convergence of valued human strengths across culture and history. Review of General Psychology, 9, 203-213.

Davis, M. H. (1983). Measuring individual differences in empathy: Evidence for a multidimensional approach. Journal of Personality and Social Psychology, 44, 113-126.

Davis, D. E., Worthington, E. L., Jr, \& Hook, J. N. (2010). Humility: Review of measurement strategies and conceptualization as personality judgment. Journal of Positive Psychology, 5, 243-252.

Davis, D. E., Hook, J. N., Worthington, E. L., Jr, Van Tongeren, D. R., Gartner, A. L., Jennings, D. J., II, \& Emmons, R. A. (2011). Relational humility: Conceptualizing and measuring humility as a personality judgment. Journal of Personality Assessment, 93, 225-234.

Davis, D. E., McElroy, S. E., Rice, K. G., Choe, E., Westbrook, C., Hook, J. N., ... Worthington, E. L. J. (2015). Is modestyasubdomain of humility? The JournalofPositivePsychology, 1-8. Advanceonlinepublication.doi: $10.1080 / 17439760.2015 .1117130$

Ekman, P., Freisen, W. V., \& Ancoli, S. (1980). Facial signs of emotional experience. Journal of Personality and Social Psychology, 39, 1125-1134.

Emmons, R. A. (1981). Relationship between narcissism and sensation seeking. Psychological Reports, $48,247-250$.

Exline, J. J. (2008). Taming the wild ego. In J. A. Bauer \& H. A. Wayment (Eds.), Transcending self-interest: Psychological explorations of the quiet ego (pp. 53-62). Washington, DC: American Psychological Association.

Exline, J. J., \& Geyer, A. L. (2004). Perceptions of humility: A preliminary study. Self and Identity, 3, 95-114.

Exline, J. J., \& Hill, P. C. (2012). Humility: A consistent and robust predictor of generosity. Journal of Positive Psychology, 7, 208-218.

Exline, J. J., Baumeister, R. F., Bushman, B. J., Campbell, W. K., \& Finkel, E. J. (2004). Too proud to let go: Narcissistic entitlement as a barrier to forgiveness. Journal of Personality and Social Psychology, 87, 894-912.

Exline, J. J., Baumeister, R. F., Zell, A. L., Kraft, A. J., \& Witvliet, C. V. (2008). Not so innocent: Does seeing one's own capability for wrongdoing predict forgiveness? Journal of Personality and Social Psychology, $94,495-515$. 
Foster, J. D., Campbell, K. W., \& Twenge, J. M. (2003). Individual differences in narcissism: Inflated selfviews across the lifespan and around the world. Journal of Research in Personality, 37, 469-486.

Fredrickson, B. L., \& Branigan, C. (2005). Positive emotions broaden the scope of attention and thoughtaction repertoires. Cognition \& Emotion, 19, 313-332.

Fredrickson, B. L., Tugade, M. M., Waugh, C. E., \& Larkin, G. R. (2003). What good are positive emotions in crises? A prospective study of resilience and emotions following the terrorist attacks on the United States on September 11th, 2001. Journal of Personality and Social Psychology, 84, 365-376.

Funder, D. C. (1995). On the accuracy of personality judgment: A realistic approach. Psychological Review, 102, 652-670.

Gosling, S. D., Rentfrow, P. J., \& Swann, W. B. (2003). A very brief measure of the Big-Five personality domains. Journal of Research in Personality, 37, 504-528.

Goncalo, J. A., Flynn, F. J., \& Kim, S. H. (2010). Are two narcissists better than one? The link between narcissism, perceived creativity, and creative performance. Personality and Social Psychology Bulletin, 36, 1484-1495.

Graziano, W. G., Jensen-Campbell, L. A., \& Hair, E. C. (1996). Perceiving interpersonal conflict and reacting to it: The case for agreeableness. Journal of Personality and Social Psychology, 70, 820-835.

Guenther, C. L., \& Alicke, M. D. (2010). Deconstructing the better-than-average effect. Journal of Personality and Social Psychology, 99, 755-770.

Harris, P. R., \& Napper, L. (2005). Self-affirmation and the biased processing of threatening health-risk information. Personality and Social Psychology Bulletin, 31, 1250-1263.

Hilbig, B. E., \& Zettler, I. (2009). Pillars of cooperation: Honesty-humility, social value orientations and economic behavior. Journal of Research in Personality, 43, 516-519.

Hobfoll, S. E. (2002). Social and psychological resources and adaptation. Review of General Psychology, 6, 307-324.

Hofstede, G. (2001). Culture's consequences (2nd ed.). Thousand Oaks, CA: Sage.

Jonason, P. K., \& Webster, G. D. (2010). The dirty dozen: A concise measure of the dark triad. Psychological Assessment, 22, 420-432.

Judge, T. A., Erez, A., \& Bono, J. E. (1998). The power of being positive: The relation between positive self-concept and job performance. Human Performance, 11, 167-187.

Kitayama, S., Markus, H. R., Matsumoto, H., \& Norasakkunkit, V. (1997). Individual and collective processes in the construction of the self: Self-enhancement in the United States and self-criticism in Japan. Journal of Personality and Social Psychology, 72, 1245-1267.

Klar, Y., \& Giladi, E. E. (1997). No one in my group can be below the group's average: A robust positivity bias in favor of anonymous peers. Journal of Personality and Social Psychology, 73, 885-901.

Kruse, E. T., Chancellor, J., Ruberton, P., \& Lyubomirsky, S. (2014). An upward spiral between gratitude and humility. Social Psychological and Personality Science, 5, 805-814.

Kruse, E. T., Chancellor, J., \& Lyubomirsky, S. (2015). Self-affirmation increases humility. Manuscript submitted for publication.

LaBouff, J. P., Rowatt, W. C., Johnson, M. K., Tsang, J., \& McCullough Willerton, G. (2012). Humble persons are more helpful than less humble persons: Evidence from three studies. Journal of Positive Psychology, 7, 16-29.

Larsen, R. J., \& Sinnett, L. M. (1991). Meta-analysis of experimental manipulations: Some factors affecting the Velten mood induction procedure. Personality and Social Psychology Bulletin, 17, 323-334.

Layous, K., Nelson, S. K., Kurtz, J. L., \& Lyubomirsky, S. (2016). What triggers prosocial effort? A positive feedback loop between positive activities, kindness, and well-being. The Journal of Positive Psychology, 1-14.

Leary, M. R., \& Guadagno, J. (2011). The role of hypo-egoic self-processes in optimal functioning and subjective well-being. In K. M. Sheldon, T. B. Kashdan, \& M. F. Steger (Eds.), Designing positive psychology: Taking stock and moving forward (pp. 135-146). Oxford: Oxford University Press.

Leary, M. R., Adams, C. E., \& Tate, E. B. (2006). Hypo-egoic self-regulation: Exercising self-control by diminishing the influence of the self. Journal of Personality, 74, 1803-1832.

Lee, K., \& Ashton, M. C. (2004). Psychometric properties of the HEXACO personality inventory. Multivariate Behavioral Research, 39, 329-358. 
Lyubomirsky, S., Dickerhoof, R., Boehm, J. K., \& Sheldon, K. M. (2011). Becoming happier takes both a will and a proper way: An experimental longitudinal intervention to boost well-being. Emotion, 11,391-402.

Maxwell, K., Donnellan, M. B., Hopwood, C. J., \& Ackerman, R. A. (2011). The two faces of Narcissus? An empirical comparison of the Narcissistic Personality Inventory and the Pathological Narcissism Inventory. Personality and Individual Differences, 50, 577-582.

McCullough, M. E., Rachal, K. C., Sandage, S. J., Worthington, E. L., Brown, S. W., \& Hight, T. L. (1998). Interpersonal forgiving in close relationships: II. Theoretical elaboration and measurement. Journal of Personality and Social Psychology, 75, 1586-1603.

McCullough, M. E., Emmons, R. A., \& Tsang, J. A. (2002). The grateful disposition: A conceptual and empirical topography. Journal of Personality and Social Psychology, 82, 112-127.

Mednick, S. A., \& Mednick, M. T. (1967). Examiner's manual, remote associates test: College and adult forms 1 and 2. Boston, MA: Houghton Mifflin.

Morris, J. A., Brotheridge, C. M., \& Urbanski, J. C. (2005). Bringing humility to leadership: Antecedents and consequences of leader humility. Human Relations, 58, 1323-1350.

Nisbett, R. E., \& Wilson, T. D. (1977). The halo effect: Evidence for unconscious alteration of judgments. Journal of Personality and Social Psychology, 35, 250-256.

Owens, B. (2009, August). The utility of humility in organizations: Establishing construct, nomological, and predictive validity. Paper presented at the annual meeting of the Academy of Management, Chicago, IL.

Owens, B. P., \& Hekman, D. R. (2012). Modeling how to grow: An inductive examination of humble leader behaviors, contingencies, and outcomes. Academy of Management Journal, 55, 787-818.

Owens, B. P., Rowatt, W. C., \& Wilkins, A. L. (2011). Exploring the relevance and implications of humility in organizations. In K. Cameron \& G. Spreitzer (Eds.), Handbook of positive organizational scholarship (pp. 260-272). Oxford: Oxford University Press.

Owens, B. P., Wallace, A. S., \& Waldman, D. A. (2015). Leader narcissism and follower outcomes: The counterbalancing effect of leader humility. Journal of Applied Psychology, 100, 1203-1213.

Paulhus, D. L. (1991). Measurement and control of response bias. In J. P. Robinson, P. R. Shaver, \& L. S. Wrightsman (Eds.), Measures of personality and social psychological attitudes (pp. 17-59). San Diego, CA: Academic Press.

Paulhus, D. L., \& John, O. P. (1998). Egoistic and moralistic biases in self-perception: The interplay of self-deceptive styles with basic traits and motives. Journal of Personality, 66, 1025-1060.

Paulhus, D. L., \& Williams, K. M. (2002). The dark triad of personality: Narcissism, machiavellianism, and psychopathy. Journal of Research in Personality, 36, 556-563.

Pincus, A. L., Ansell, E. B., Pimentel, C. A., Cain, N. M., Wright, A. G., \& Levy, K. N. (2009). Initial construction and validation of the Pathological Narcissism Inventory. Psychological Assessment, 21, 365-379.

Pratto, F., Sidanius, J., Stallworth, L. M., \& Malle, B. F. (1994). Social dominance orientation: A personality variable predicting social and political attitudes. Journal of Personality and Social Psychology, 67, 741-763.

Pyszczynski, T., \& Greenberg, J. (1987). Self-regulatory perseveration and the depressive self-focus style: A self-awareness theory of reactive depression. Psychological Bulletin, 102, 122-138.

Raskin, R. N., \& Hall, C. S. (1979). A narcissistic personality inventory. Psychological Reports, 45, 590-590.

Raskin, R. N., \&Terry, H. (1988). A principal-components analysis of the Narcissistic Personality Inventory and further evidence of its construct validity. Journal of Personality and Social Psychology, 54, 890-902.

Rhodewalt, F., \& Morf, C. C. (1998). On self-aggrandizement and anger: A temporal analysis of narcissism and affective reactions to success and failure. Journal of Personality and Social Psychology, 74, 672.

Roberts, B. W., Edmonds, G., \& Grijalva, E. (2010). It is developmental me, not generation me: Developmental changes are more important than generational changes in narcissism - Commentary on Trzesniewski \& Donnellan (2010). Perspectives on Psychological Science, 5, 97-102.

Rosenberg, M. (1965). Society and the adolescent self-image. Princeton, NJ: Princeton University Press. Rowatt, W. C., Powers, C., Targhetta, V., Comer, J., Kennedy, S., \& Labouff, J. (2006). Development and initial validation of an implicit measure of humility relative to arrogance. Journal of Positive Psychology, 1, 198-211. 
Ruberton, P. M., Huynh, H., Miller, T. A., Kruse, E., Chancellor, J., \& Lyubomirsky, S. (2016). The relationship between physician humility, physician-patient communication, and patient health. Patient Education and Counseling, 99, 1138-1145.

Ruberton, P. M., Kruse, E., \& Lyubomirsky, S. (2016). Boosting state humility via gratitude, self-affirmation, and awe: Theoretical and empirical perspectives. In E. Worthington, D. Davis, \& J. Hook (Eds.), Handbook of humility. New York, NY: Routledge.

Scherer, K. R. (1997). The role of culture in emotion-antecedent appraisal. Journal of Personality and Social Psychology, 73, 902-922.

Schwartz, S. H. (1994). Beyond individualism/collectivism: New cultural dimensions of values. In U. Kim, H. C. Triandis, C. Kagitcibasi, S. Choi, \& G. Yoon (Eds.), Individualism and collectivism: Theory, method and applications (pp. 85-119). Thousand Oaks, CA: Sage.

Sedikides, C., Gregg, A. P., \& Hart, C. M. (2008). The importance of being modest. In C. Sedikides \& S. Spencer (Eds.), The self: Frontiers in social psychology (pp. 163-184). New York, NY: Psychology Press.

Seligman, M. E., Steen, T. A., Park, N., \& Peterson, C. (2005). Positive psychology progress. American Psychologist, 60, 410-421.

Smith, C. A., \& Ellsworth, P. C. (1985). Patterns of cognitive appraisal in emotion. Journal of Personality and Social Psychology, 48, 813.

Spreitzer, G. M., \& Sonenshein, S. (2004). Toward the construct definition of positive deviance. American Behavioral Scientist, 47, 828-847.

Stucke, T. S., \& Sporer, S. L. (2002). When a grandiose self-image is threatened: Narcissism and selfconcept clarity as predictors of negative emotions and aggression following ego-threat. Journal of Personality, 70, 509-532.

Tangney, J. P. (2000). Humility: Theoretical perspectives, empirical findings and directions for future research. Journal of Social and Clinical Psychology, 19, 70-82.

Tangney, J. P., Stuewig, J., \& Mashek, D. J. (2007). Moral emotions and moral behavior. Annual Review of Psychology, 58, 345-372.

Tomaka, J., \& Blascovich, J. (1994). Effects of justice beliefs on cognitive appraisal of and subjective physiological, and behavioral responses to potential stress. Journal of Personality and Social Psychology, 67, 732-740.

Tracy, J. L., \& Robins, R. W. (2007). The psychological structure of pride: A tale of two facets. Journal of Personality and Social Psychology, 92, 506-525.

Twenge, J. M., \& Campbell, W. K. (2009). The narcissism epidemic: Living in the age of entitlement. New York, NY: Free Press.

Twenge, J. M., \& Foster, J. D. (2010). Birth cohort increases in narcissistic personality traits among American college students, 1982-2009. Social Psychological and Personality Science, 1, 99-106.

Twenge, J. M., Konrath, S., Foster, J. D., Keith Campbell, W., \& Bushman, B. J. (2008). Egos inflating over time: A cross-temporal meta-analysis of the Narcissistic Personality Inventory. Journal of Personality, 76, 875-902.

Velten, E. (1968). A laboratory task for induction of mood states. Behavior Research and Therapy, 6, 473-482.

Watson, D., Clark, L. A., \& Tellegen, A. (1988). Development and validation of brief measures of positive and negative affect: The PANAS scales. Journal of Personality and Social Psychology, 54, 1063-1070.

Wright, A. G., Lukowitsky, M. R., Pincus, A. L., \& Conroy, D. E. (2010). The higher order factor structure and gender invariance of the Pathological Narcissism Inventory. Assessment, 17, 467-483. 


\section{Appendix 1.Brief state humility scale (BSHS)}

Please answer these questions based on how you feel right this moment.

\begin{tabular}{lcccccc}
\hline $\begin{array}{l}\text { Strongly } \\
\text { disagree }\end{array}$ & Disagree & Slightly disagree & $\begin{array}{c}\text { Neither agree nor } \\
\text { disagree }\end{array}$ & $\begin{array}{c}\text { Slightly } \\
\text { agree }\end{array}$ & Agree & $\begin{array}{c}\text { Strongly } \\
\text { agree }\end{array}$ \\
\hline 1 & 2 & 3 & 4 & 5 & 6 & 7 \\
\hline
\end{tabular}

(1) I feel that, overall, I am no better or worse than the average person.

(2) I feel that I have both many strengths and flaws.

(3) I feel that I do not deserve more respect than other people.

(4) To be completely honest, I feel that I am better than most people.

(5) I feel that I deserve more respect than everyone else.

(6) I feel that I do not have very many weaknesses.

Items 4-6 are reverse-scored.

\section{Appendix 2}

Values affirmation

You selected as one of your greatest values: [Greatest Value]

Please write about why this value is important to you. Write at least a short paragraph. Please do not include any identifying details (such as your name).

Values control

You selected as one of your least values: [Lowest Value]

Please write about why this value might be important to someone else. Write at least a short paragraph. Please do not include any identifying details (such as your name).

\section{Anger prompt}

Imagine that someone is angry with you. Why are they angry with you? What led up to them being angry with you? How do you feel about the situation? Write $4-5$ sentences (do not write a 1-2 sentence answer). Please do not include any identifying details (such as your name).

Gratitude

Think of the people - parents, friends, teachers, coaches, teammates, employers, and so on - who have been especially kind to you but have never heard you express your gratitude. Write a letter expressing gratitude to one of these individuals, describing in specific terms why you are grateful. Specify in detail what they did for you, and exactly how it affected your life (but do not include any identifying information, such as names). Describe what you are doing now and how you often remember their efforts. Write 4-5 sentences (do not write a 1-2 sentence answer).

Hubristic pride

In as much detail as you can remember, recall and describe a time that you behaved in a self-important manner, or felt pretentious or stuck-up. Write at least 4-5 sentences (do not write a 1-2 sentence answer). Please do not include any identifying details (such as your name).

Neutral control (Gratitude and pride experiments)

Think about what you did for the two hours prior to this study. Write about what you did, but in neutral terms, like you were simply stating what happened as facts. Write 4-5 sentences (do not write a 1-2 sentence answer). Please do not include any identifying details (such as your name).

Deviance vignette

Imagine you are at your workplace and your team has come up with a solution to a major problem that had been plaguing your company. Everyone, including your boss, has agreed that it is the best plan and that there are no other good solutions. Your boss presents it to their boss, who says to go ahead with your team's idea. 
However, a week later, you realize there is actually a fatal problem in the plan. You know that, previously, when someone had spoken up about a problem on an earlier project, your boss had argued with them at a meeting and called them a "loudmouth" that "just wants attention." Overall, the boss had made them look arrogant. 